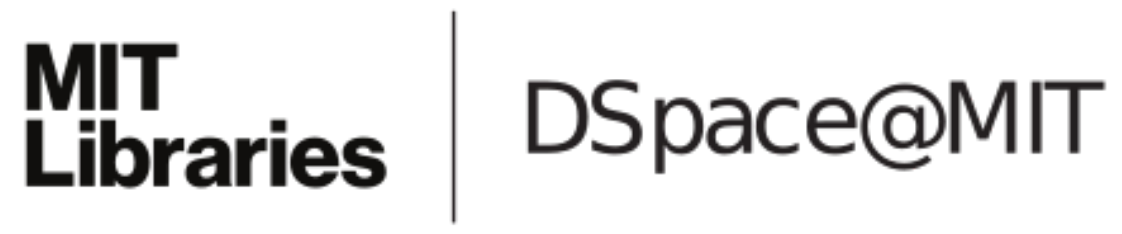

\author{
MIT Open Access Articles
}

\section{Parameterization of mixed layer eddies. III: Implementation and impact in global ocean climate simulations}

The MIT Faculty has made this article openly available. Please share how this access benefits you. Your story matters.

Citation: Fox-Kemper, B., G. Danabasoglu, R. Ferrari, S.M. Griffies, R.W. Hallberg, M.M. Holland, M.E. Maltrud, S. Peacock, and B.L. Samuels. "Parameterization of Mixed Layer Eddies. III: Implementation and Impact in Global Ocean Climate Simulations." Ocean Modelling 39, no. 1-2 (January 2011): 61-78.

As Published: http://dx.doi.org/10.1016/j.ocemod.2010.09.002

Publisher: Elsevier

Persistent URL: http://hdl.handle.net/1721.1/99135

Version: Author's final manuscript: final author's manuscript post peer review, without publisher's formatting or copy editing

Terms of use: Creative Commons Attribution-Noncommercial-NoDerivatives 


\title{
Parameterization of Mixed Layer Eddies. III: Implementation and Impact in Global Ocean Climate Simulations
}

\author{
B. Fox-Kempera , G. Danabasoglu ${ }^{\mathrm{b}}$, R. Ferrari ${ }^{\mathrm{c}}$, S. M. Griffies ${ }^{\mathrm{d}}$, R. W. \\ Hallberg $^{\mathrm{d}}$, M. M. Holland ${ }^{\mathrm{b}}$, M. E. Maltrud ${ }^{\mathrm{e}}$, S. Peacock ${ }^{\mathrm{b}}$, B. L. Samuels ${ }^{\mathrm{d}}$ \\ ${ }^{a}$ Cooperative Institute for Research in Environmental Sciences (CIRES) and Dept. of \\ Atmospheric and Oceanic Sciences (ATOC), University of Colorado, Boulder, Colorado \\ ${ }^{b}$ National Center for Atmospheric Research, Boulder, Colorado \\ ${ }^{c}$ MIT Dept. of Earth, Atmospheric, and Planetary Sciences, Cambridge, Massachusetts \\ ${ }^{d}$ NOAA Geophysical Fluid Dynamics Laboratory, Princeton, New Jersey \\ ${ }^{e}$ Fluid Dynamics Group, Los Alamos National Laboratory, Los Alamos, New Mexico
}

\begin{abstract}
A parameterization for the restratification by finite-amplitude, submesoscale, mixed layer eddies, formulated as an overturning streamfunction, has been recently proposed to approximate eddy fluxes of density and other tracers. Here, the technicalities of implementing the parameterization in the coarseresolution ocean component of global climate models are made explicit, and the primary impacts on model solutions of implementing the parameterization are discussed. Three global ocean general circulation models including this parameterization are contrasted with control simulations lacking the parameterization. The MLE parameterization behaves as expected and fairly consistently in models differing in discretization, boundary layer mixing, resolution, and other parameterizations. The primary impact of the parameterization is a shoaling of the mixed layer, with the largest effect in polar winter regions. Secondary impacts include strengthening the Atlantic meridional overturning while reducing its variability, reducing $\mathrm{CFC}$ and tracer ventilation, modest changes to sea surface temperature and air-sea fluxes, and an apparent reduction of sea ice basal melting.
\end{abstract}

Keywords: Submesoscale, parameterization, mixed layer, boundary layer, climate model 


\section{Introduction}

The world ocean surface is filled with fronts. Many are formed by mesoscale eddies straining large-scale density gradients into concentrated filamentsdensity fronts-that are further sharpened near the surface by ageostrophic circulations (Hoskins and Bretherton, 1972; Pollard and Regier, 1992). Patchy mixing by isolated events (e.g., hurricanes) combined with large-scale strain may also lead to horizontal density gradients (e.g., Price, 1981; Ferrari and Rudnick, 2000; D'Asaro et al., 2007; Price et al., 2008). A front stores potential energy in the horizontal juxtaposition of dense and light water masses; slumping of the front releases potential energy. However, the energy release is limited by Rossby adjustment, where a Coriolis force develops with an along-front flow to balance the cross-front pressure gradient and prevent further slumping (e.g., Tandon and Garrett, 1994). Rossby-adjusted density fronts are commonly observed throughout the ocean mixed layer (Rudnick and Ferrari, 1999; Ferrari and Rudnick, 2000; Hosegood et al., 2006).

Rossby-adjusted fronts are often unstable to mixed layer instabilities (MLIs: Boccaletti et al., 2007; Samelson and Chapman, 1995; Haine and Marshall, 1998). These ageostropic baroclinic instabilities grow and form mixed layer eddies (MLEs) when they reach finite amplitude. MLIs resemble the ageostrophic baroclinic instabilities studied by Stone (1970) in his analysis of the Eady (1949) problem of constant geostrophic shear and stratification. Stone finds a linear growth rate of

$$
\begin{array}{r}
\tau_{s}(k)=\frac{k U}{2 \sqrt{3}}\left[1-\frac{2 k^{2} U^{2}}{15 f^{2}}(1+\mathrm{Ri})\right], \\
\operatorname{Ri}=N^{2}\left|\frac{\partial \boldsymbol{u}_{g}}{\partial z}\right|^{-2}=\frac{N^{2} H^{2}}{U^{2}} .
\end{array}
$$

The scale depends on the geostrophic-flow Richardson number, Ri (Boccaletti et al., 2007). The fastest growing linear mode has length and time scales $L_{s}$ and $\tau_{s}$.

$$
\begin{aligned}
L_{s}=\frac{2 \pi}{k_{s}} & =\frac{2 \pi U}{|f|} \sqrt{\frac{1+\mathrm{Ri}}{5 / 2}}, \\
\tau_{s}\left(k_{s}\right) & =\sqrt{\frac{54}{5}} \frac{\sqrt{1+\mathrm{Ri}}}{|f|} .
\end{aligned}
$$

Email address: bfk@colorado.edu (B. Fox-Kemper) 
As MLIs become finite amplitude MLEs, the front slumps beyond the Rossbyadjusted state and continues to release potential energy.The overall slumping results in substantial restratification of the mixed layer and shields the themocline from subsequent mixing events.

Fox-Kemper et al. (2008b) propose a parameterization to predict this MLE-induced restratification and related effects. While much of the implementation is detailed in Fox-Kemper and Ferrari (2008), additional details necessary for implementing this parameterization in coarse-resolution global ocean models will be presented here. The parameterization has been extensively validated to approximate well the results of idealized high-resolution simulations of slumping of a single mixed layer front (Fox-Kemper and Ferrari, 2008), but this work extends the scaling for one front to a field of fronts based on frontal statistics from data and models.

The length and time scales of MLIs fall in the submesoscale $O(1 \mathrm{~km}, 1$ day $)$ range, for typical mixed layer depth $(H)$ and stratification $(N)$ are small, and therefore MLI are smaller and faster than mesoscale instabilities. MLEs are somewhat larger in scale than MLIs due to an inverse cascade (Boccaletti et al., 2007), but remain limited to the submesoscale range (Fox-Kemper et al., 2008b). Thus, MLIs and MLEs will not be directly resolved in globalscale simulations for some time.

It will be shown here that MLE restratification, as represented by the parameterization, is important in coarse resolution models despite the small size of individual MLEs. Basin-scale simulations at MLE-permitting $2 \mathrm{~km}$ resolution have shown bias reduction in near-surface properties (e.g., Oschlies, 2002; Lévy et al., 2010), and preliminary results of the MLE parameterization effects in coarse models show encouraging bias reduction compared to climatology (Fox-Kemper et al., 2008a). This paper documents the most notable effects of the MLE parameterization by comparing global climate simulations using the parameterization with otherwise identical control simulations not using the MLE parameterization. These results are intended as a guide when considering and implementing the MLE parameterization in climate models. Readers interested only in the results of implementing the MLE parameterization and not the details of its implementation may skip ahead to Section 3.

Other submesoscale effects-wind-front and convection-front interactions, and frontogenesis-remain unparameterized at present. Thomas and Ferrari (2008) derive scalings and find comparable magnitudes for all of these physical phenomena. However, Mahadevan et al. (2010) and Capet et al. (2008a) 
show that even in complex, realistic settings and in the presence of moderate winds, the MLE-induced overturning described here remains qualitatively adept at describing submesoscale restratification. Additional restratification and straining by mesoscale eddies (Lapeyre et al., 2006), restratification by up-front winds and destratification by down-front winds (Thomas and Lee, 2005), and restratification by symmetric instabilities (Taylor and Ferrari, 2009) remain unparameterized in the models presented here. These effects have been shown to affect the rate of MLE-induced overturning in some situations (Spall, 1995; Mahadevan et al., 2010). However, Mahadevan et al. (2010) conclude that 'the net advective buoyancy flux is the sum of the advective effect of eddies and the mean wind-driven circulation,' so it seems possible to parameterize these effects independently.

Submesoscale fronts and frontal restratification and instabilities also affect biology (Levy et al., 1999; Spall and Richards, 2000; Mahadevan and Archer, 2000; Klein and Lapeyre, 2009). The MLE parameterization described here will impact the physical environment and nutrient transport properties of the photic zone if used for biogeochemical modeling, but it is presently unclear whether the use of the MLE parameterization alone is beneficial to biogeochemical modeling. Other submesoscale dynamics are likely to impact biology to a similar degree and biology may interfere with the proper scaling of MLE nutrient transport (Section 2.1.2). Resolving relevant submesoscale dynamics in global models for century-long simulations will be too expensive for some time, so parameterized submesoscale processes is presently the only viable way to assess their global climate impact. This paper begins the process of understanding the impact of submesoscale physics on global climate, and future parameterization refinements are likely to further improve global climate modeling and understanding.

\section{Implementation in Global Coarse Ocean Models}

The Fox-Kemper et al. (2008b) parameterization is cast as an MLEinduced overturning vector streamfunction $(\boldsymbol{\Psi})$, which produces an MLEinduced or quasi-Stokes velocity field $\left(\mathbf{u}^{*}=\nabla \times \boldsymbol{\Psi}\right)$. Advection by the MLE-induced velocity acts to slump fronts and provides eddy fluxes of tracers $\left(\overline{\mathbf{u}^{\prime} c^{\prime}}=\Psi \times \nabla \bar{c}\right)$.

Three parameters enter in the parameterization: the mixed layer depth, the horizontal buoyancy gradient in the mixed layer, and the Earth's rotation rate. Buoyancy is the negative density anomaly rescaled to have dimensions 
of acceleration $b \equiv g\left(\rho_{0}-\rho\right) / \rho_{0}$, where $\rho_{0}$ is the constant reference density associated with the Boussinesq approximation. Throughout, overlines are used to represent the fields in a coarse-resolution model, that is, one not resolving the submesoscale eddies. As will be shown below, a scaling factor will account for how coarse the model resolution is-it may be mesoscale resolving or coarser. In any case, the primed quantities here always refer to submesoscale fluxes, not to resolved or parameterized mesoscale fluxes. The MLE fluxes are to be added to resolved or parameterized mesoscale eddy fluxes and to any additional parameterized finescale turbulent fluxes.

The MLE parameterization of Fox-Kemper et al. (2008b) is given by

$$
\begin{gathered}
\boldsymbol{\Psi}_{0}=C_{e} \frac{H^{2} \nabla \bar{b}^{z} \times \hat{\mathbf{z}}}{|f|} \mu(z), \\
\mu(z)=\max \left\{0,\left[1-\left(\frac{2 z}{H}+1\right)^{2}\right]\left[1+\frac{5}{21}\left(\frac{2 z}{H}+1\right)^{2}\right]\right\},
\end{gathered}
$$

where $H$ is mixed layer depth, $f$ is the Coriolis parameter, and $\hat{\mathbf{z}}$ is the unit vertical vector. The subscript 0 is to indicate that this is the original form appropriate for extratropical, mesoscale-resolving models. A modified form appropriate for coarse-resolution global models is given below. The overline with subscript $z$ on $\nabla \bar{b}^{z}$ is understood to be the depth-average of $\nabla \bar{b}$ over the mixed layer. The efficiency coefficient $C_{e}$ is found to be $0.06-0.08$ from MLE-resolving simulations (Fox-Kemper et al., 2008b).

An adaptation to (5) that is suitable and justified in a global coarseresolution model is

$$
\boldsymbol{\Psi}=C_{e} \frac{\Delta s}{L_{f}} \frac{H^{2} \nabla \bar{b}^{z} \times \hat{\mathbf{z}}}{\sqrt{f^{2}+\tau^{-2}}} \mu(z) .
$$

The local coarse model gridscale dimension is $\Delta s$, and $L_{f}$ is an estimate of the typical local width of mixed layer fronts (Section 2.1). No compelling theory for the width of oceanic mixed layer fronts is known to the authors (Hoskins and Bretherton, 1972; Blumen and Piper, 1999, discuss atmospheric frontal scales), but the observations of Hosegood et al. (2006) suggest $L_{f}$ is close to the mixed layer deformation radius $N H / f$, where $N$ is the buoyancy frequency based on the mixed layer stratification. To guarantee stability, most of the models described below use a limiting value of $L_{f}$, called $L_{f, m i n}$. So $L_{f}=\max \left(N H /|f|, L_{f, \min }\right)$ where $L_{f, \min }$ is 0.2 to $5 \mathrm{~km}$ (Section 2.1.4). The timescale $\tau$ is roughly the time needed to mix momentum across the mixed layer $(\approx 1-10$ days, see Section 2.3$)$. The reasoning behind the modifications 
of (5) to (6) will be explained in sections 2.1 and 2.3. Other materiallyconserved tracers-such as salinity, potential temperature, and nutrients-are also advected by the MLE-overturning at fronts. Therefore, all of the models here use the MLE streamfunction in (6) to advect all tracers (Section 3.3).

The MLE parameterization has been successfully included in a number of ocean models differing in discretization, subgrid parameterizations, and nominal resolution from $0.1^{\circ}$ to $3^{\circ}$ (POP2, MOM4p1, GOLD, MITgcm: Smith et al., 2010; Griffies, 2009; Adcroft and Hallberg, 2006; Marshall et al., 1997, respectively). From these models, the parameterization impact in ocean-only and coupled climate simulations are discussed in Section 3 and implementation details are in Table 1 and the Appendices.

Table 1: Model simulations discussed in the text. Superscript \pm indicate inclusion of the MLE parameterization.

\begin{tabular}{|c|c|c|c|c|c|c|c|}
\hline Model & Grid & Resolution & $\begin{array}{c}\text { Vert. } \\
\text { Coord. }\end{array}$ & Mixing & $\begin{array}{c}\text { Run } \\
\text { Length }\end{array}$ & $\begin{array}{c}\text { Analysis } \\
\text { Window }\end{array}$ & $\begin{array}{c}\text { Forcing/ } \\
\text { Atmos. }\end{array}$ \\
\hline \hline${\text { NY } / \mathrm{POP}^{ \pm}}^{ \pm}$ & B-grid & nom. $1^{\circ}$ tripole & $60 \mathrm{z}$ & KPP & $272 \mathrm{yr}$ & yr 153-172 & Norm. Yr., CICE4 \\
\hline $\mathrm{CCSM}^{ \pm}$ & B-grid & nom. $1^{\circ}$ tripole & $60 \mathrm{z}$ & KPP & $172 \mathrm{yr}$ & yr 153-172 & CAM4, CICE4, CLM4 \\
\hline${\mathrm{CM} 2 \mathrm{M} \alpha^{ \pm}}^{\text {B-grid }}$ & nom. $1^{\circ}$ tripole & $50 \mathrm{z}^{*}$ & KPP & $300 \mathrm{yr}$ & yr 181-200 & AM2.1, SIS, LM3 \\
\hline $\mathrm{CM} 2 \mathrm{G} \alpha^{ \pm}$ & C-grid & nom. $1^{\circ}$ tripole & $4 \mathrm{ML} \& 59 \rho$ & Hallberg & $300 \mathrm{yr}$ & yr 181-200 & AM2.1, SIS, LM3 \\
\hline $\mathrm{MESO}^{-}$ & C-grid & $2^{\circ}$ to $\frac{1}{6}^{\circ}$, mercator & $3 \mathrm{ML} \mathrm{\& 20 \rho}$ & Hallberg & $40 \mathrm{yr}$ & yr 20-40 & Climatology \\
\hline POP-HI $^{ \pm}$ & B-grid & nom. $0.1^{\circ}$ tripole & $40 \mathrm{z}$ & KPP & $1 \mathrm{mo}$ & $1 \mathrm{mo}$ & Norm. Yr. \\
\hline
\end{tabular}

\subsection{Accounting for Weaker Density Gradients in Coarse Models}

The MLE parameterization (5) is proportional to the horizontal density gradient, a quantity that depends strongly on horizontal resolution. Coarser models have weaker gradients than finer, and sparser observations have weaker gradients than denser. Additionally, the MLE parameterization in (5) is based on one resolved front, rather than a sea of statisticallydistributed fronts of varying strength and orientation. Fortunately, one can scale for these effects based on an analysis of the horizontal wavenumber spectrum of near-surface density variance. The $\Delta s / L_{f}$ factor in (6) is the result of this analysis (Section 2.1.3). This rescaling can be done with some confidence, as the same near-surface density variance spectrum is found in observations (Section 2.1.1) and in model hierarchies designed to study the effects of differing resolution (Section 2.1.2). 


\subsubsection{Scaling of Horizontal Gradients in Data}

The SeaSoar observations of Ferrari and Rudnick (2000) sample the velocity (by ADCP) and temperature, salinity, and density (by CTD) of the midPacific near-surface ocean over horizontal lengthscales ranging from $100 \mathrm{~m}$ to $100 \mathrm{~km}$. Both kinetic energy (not shown) and the potential density variance spectra scale with nearly $k^{-2}$ over this range (Figure 1). A spectral slope, while sufficient for our purposes, is not sufficient to distinguish the physical processes generating it. This scaling is consistent both with ubiquitous fronts (Capet et al., 2008d) and many other rationales. Similar $k^{-2}$ horizontal wavenumber scalings of mixed layer density, and mixed layer tracer variance are found elsewhere in a variety of instrumental records (e.g., Katz, 1975; Ewart, 1976; Dugan et al., 1986; Samelson and Paulson, 1988; Strass, 1992; Hodges and Rudnick, 2006; Hosegood et al., 2006; Cole et al., 2009). Consistently, altimetric velocities display a near $k^{-2}$ rolloff at high wavenumbers, although noise-contamination is an issue (Le Traon et al., 2008).

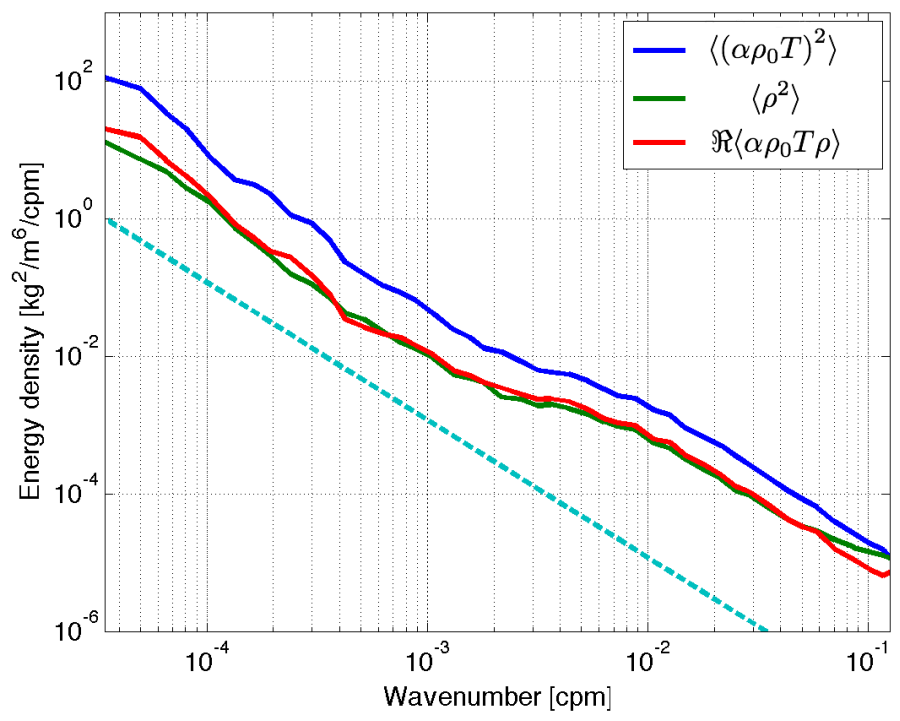

Figure 1: Observed spectra of mixed layer potential density variance (green), temperature contribution to potential density (blue), and temperature-density co-spectrum (red) from SeaSoar towed CTD and shipboard ADCP sections (data from Ferrari and Rudnick, 2000). A dashed line indicates $k^{-2}$ scaling. 


\subsubsection{Resolution Scaling of Horizontal Gradients in a Model}

The MESO simulations of Hallberg and Gnanadesikan (2006) constitute a set of 5 directly comparable simulations of the Southern Ocean at different resolutions ranging from very coarse $\left(2^{\circ}\right)$ to eddy-rich $\left(1 / 6^{\circ}\right)$. Figure 2 shows that the zonal mean, $\left\langle\left|\nabla_{H} \rho\right|^{2}\right\rangle$ in these simulations is proportional to $1 / \Delta s$ among these models for all resolutions finer than $1^{\circ}$ (angle brackets denote a horizontal average). The next section will show that this scaling for the magnitude of $\left\langle\left|\nabla_{H} \rho\right|^{2}\right\rangle$ with gridscale is consistent with a $k^{-2}$ buoyancy spectrum as found in data. Other numerical model sets at differing resolution find agreement with the $k^{-2}$ density variance scaling as well (Capet et al., 2008b; Klein et al., 2008), with important energetic consequences (Capet et al., 2008d).
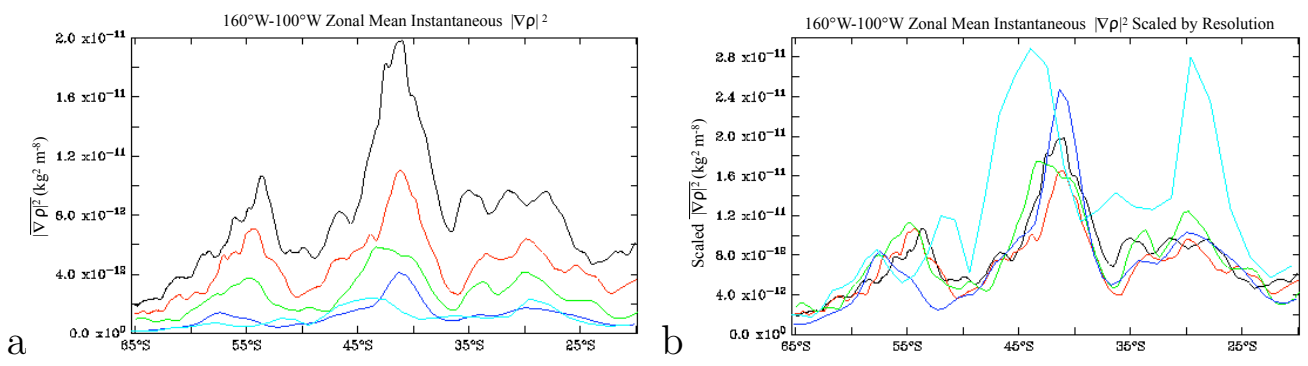

Figure 2: (a) Zonal mean of $\left|\nabla_{H} \rho\right|^{2} \equiv \frac{\rho_{0}}{g}\left|\nabla_{H} b\right|^{2} \mid$ in Southern Ocean simulations at different resolutions $\left(\operatorname{cyan}=2^{\circ}\right.$, blue $=1^{\circ}$, green $=1 / 2^{\circ}$, red $=1 / 4^{\circ}$, and black $\left.=1 / 6^{\circ}\right)$, and $(\mathrm{b})$ $\left|\nabla_{H} \rho\right|^{2}$ rescaled by $\Delta s$. The scaling collapses the data except for the coarsest resolution model.

Not only do the zonal mean and spectral slope have a consistent scaling for stronger buoyancy gradients in higher resolution models, but the pattern of buoyancy gradients from location to location scales consistently as well. Figure 3 shows that that the spatial pattern of $\left\langle\left|\nabla_{H} \rho\right|^{2} \Delta s\right\rangle$ in the eddy-rich $1 / 6^{\circ}$ model, when averaged onto a $1^{\circ}$ grid, is locally of very similar magnitude to $\left|\nabla_{H} \rho\right|^{2} \Delta s$ resolved in the $1^{\circ}$ model.

\subsubsection{Scaling MLE restratification with Gridscale}

Fox-Kemper et al. (2008b) argue that the crucial MLE process to reproduce is the vertical buoyancy flux $\overline{w^{\prime} b^{\prime}}$, because the net upward motion of light water and the sinking of dense water is a direct measure of fluid restratification. This section will prove that this vertical flux can be made 


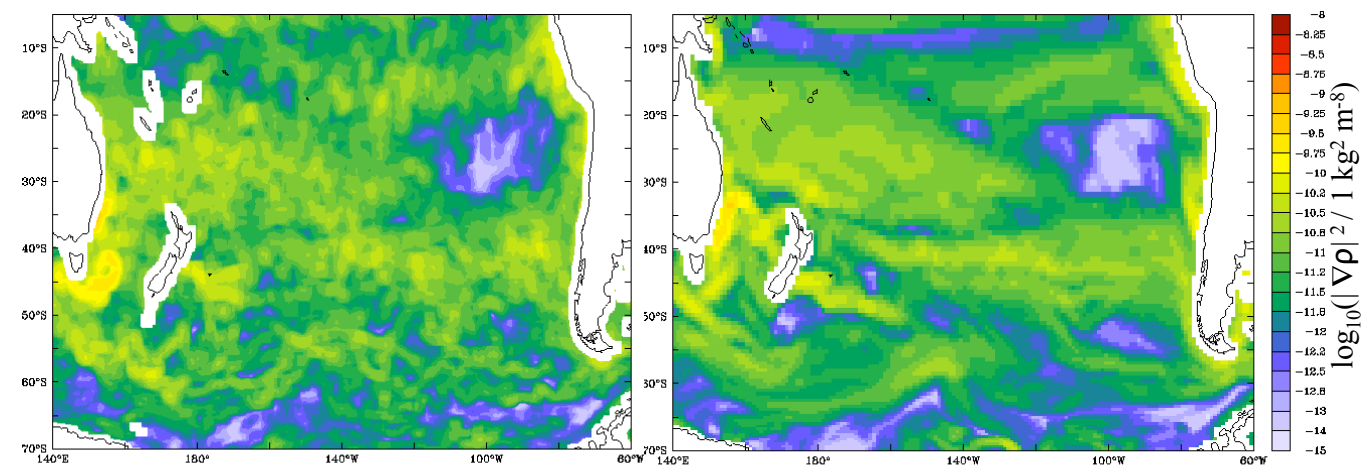

Figure 3: Southern Ocean simulation scaled $\left|\nabla_{H} \rho\right|^{2} \equiv \frac{\rho_{0}}{g}\left|\nabla_{H} b\right|^{2} \mid$ in two different resolution simulations. On left, $\left|\nabla_{H} \rho\right|^{2}$ in a $1 / 6^{\circ}$ degree simulation (averaged onto a $1^{\circ}$ grid) and on right $6\left|\nabla_{H} \rho\right|^{2}$ in a $1^{\circ}$ degree simulation with the same color scaling.

independent of model resolution if the buoyancy spectral slope is locally $k^{-2}$ as found in data and models in the preceding sections. The vertical flux given by (5) scales as

$$
\overline{w^{\prime} b^{\prime}} \equiv \Psi \times \nabla \bar{b} \approx \Psi \times \nabla \bar{b}^{z} \propto \frac{H^{2}\left|\nabla_{H} \bar{b}^{z}\right|^{2}}{|f|} .
$$

One would like the vertical buoyancy flux to be independent of model resolution, but $\left|\nabla_{H} \bar{b}^{z}\right|^{2}$ depends on model resolution. ${ }^{1}$ However, the dependence on resolution is $\left\langle\left|\nabla_{H} \bar{b}^{z}\right|^{2}\right\rangle \propto 1 / \Delta s$ according to Figs. 2-3. The following derivation will show that this rescaling is consistent with the $k^{-2}$ density spectrum from observations.

Suppose $B(k)$ is the isotropic power spectral density of buoyancy at horizontal wavenumber $k$. If the data is spatially homogeneous, then each subinterval constituting the $B(k)$ spectrum will have the same spectrum. Thus, the average of small scale gradients over a subinterval of arbitrary length $L$

${ }^{1} \mathrm{~A}$ nontrivial correlation of mixed layer depth and density gradient $\left\langle H^{2}\left|\nabla_{H} \bar{b}^{z}\right|^{2}\right\rangle \neq$ $\left\langle H^{2}\right\rangle\left\langle\left|\nabla_{H} \bar{b}^{z}\right|^{2}\right\rangle$ may result from fronts that differ in mixed layer depth from their surroundings. However, numerical MLE-resolving experiments of fronts over varying mixed layer depth versus the predictions of (5) seem to scale better with the average MLD across the front than the extremal values inside or outside of the front. Nonetheless, closer examination is warranted. 
is

$$
\begin{aligned}
\int_{0}^{L} \int_{0}^{2 \pi}\left|\bar{b}^{z}\right|^{2} r \mathrm{~d} r \mathrm{~d} \theta & =\int_{\frac{2 \pi}{L}}^{\infty} B(k) \mathrm{d} k \\
\int_{0}^{L} \int_{0}^{2 \pi}\left|\nabla_{H} \bar{b}^{z} \hat{\mathbf{z}}\right|^{2} r \mathrm{~d} r \mathrm{~d} \theta & =\int_{\frac{2 \pi}{L}}^{\infty} k^{2} B(k) \mathrm{d} k .
\end{aligned}
$$

Fig. 1 shows $B(k) \propto k^{-2}$ in observations from $1^{\circ}$ to the smallest scales measured.

Hosegood et al. (2006) argue that the buoyancy variance drops off quickly near the mixed layer deformation radius. ${ }^{2}$ However, sampling at some sufficiently small scale $L_{f}$, a single front of a characteristic strength will be resolved and additional sampling will not increase its density gradient. Thus, smaller scales may be neglected from the integral. For $L>L_{f}$,

$$
\int_{0}^{L} \int_{0}^{2 \pi}\left|\nabla_{H} \bar{b}^{z}\right|^{2} r \mathrm{~d} r \mathrm{~d} \theta=\int_{\frac{2 \pi}{L}}^{\infty} k^{2} B(k) \mathrm{d} k=\int_{\frac{2 \pi}{L}}^{\frac{2 \pi}{L_{f}}} B_{0} \mathrm{~d} k
$$

where $B_{0}$ is a constant.

The average MLE restratification is to be resolution-independent regionally in a coarse-grain model. That is, the MLE restratification, when averaged over a region of size $L_{b}$ larger than the coarse-grain gridscale (i.e., $\left.L_{b} \gg \Delta s\right)$, ought to be independent of resolution $(\Delta s)$. Furthermore, the front width, $L_{f}$, where density variance drops off, is smaller than $\Delta s$ in models where MLEs need to be parameterized. Overall, if $L_{b} \gg \Delta s \gg L_{f}$ and $B(k) \propto B_{0} k^{-2}$, then the resolved buoyancy gradient (averaged over $L_{b}$ ) should scale compared to the full buoyancy gradient (averaged over $L_{b}$ ) as

$$
\begin{aligned}
\frac{\int_{\Delta s}^{L_{b}} \int_{0}^{2 \pi}\left|\nabla_{H} \bar{b}^{z}\right|^{2} r \mathrm{~d} r \mathrm{~d} \theta}{\int_{0}^{L_{b}} \int_{0}^{2 \pi}\left|\nabla_{H} \bar{b}^{z}\right| 2 r \mathrm{~d} r \mathrm{~d} \theta} & =\frac{\int_{\frac{2 \pi}{L_{b}}}^{\frac{2 \pi}{\Delta s}} B_{0} \mathrm{~d} k}{\int_{\frac{2 \pi}{L_{b}}}^{\frac{2 \pi}{L_{f}}} B_{0} \mathrm{~d} k} \\
& =\frac{L_{f}}{\Delta s} \frac{L_{b}-\Delta s}{L_{b}-L_{f}} \\
& \approx \frac{L_{f}}{\Delta s} .
\end{aligned}
$$

\footnotetext{
${ }^{2}$ However, it is not clear in their figures whether the drop represents steeper spectral slope.
} 
Thus, the average, $\left\langle\left|\nabla_{H} \bar{b}^{z}\right|^{2} \Delta s / L_{f}\right\rangle$, over a scale $L_{b}$ is approximately independent of $\Delta s$. Indeed, Fig. 2 shows that the average of $\left\langle\left|\nabla_{H} \bar{b}^{z}\right|^{2} \Delta s\right\rangle$ is approximately independent of $\Delta s$ in a hierarchy of numerical models with $\Delta s$ ranging from coarse $\left(1^{\circ}\right)$ to mesoscale-permitting $\left(1 / 6^{\circ}\right)$. Fig. 3 shows that this $\Delta s$ scaling holds fairly well even over relatively small regions $\left(L_{b} \approx 1^{\circ}\right)$.

Likewise, rescaling

$$
\Psi \propto \Psi_{0} \frac{\Delta s}{L_{f}}
$$

suffices to make $\overline{w^{\prime} b^{\prime}}$ independent of $\Delta s$. The streamfunction formulation ensures that $\overline{v^{\prime} b^{\prime}}$ will adapt as needed for conservation, although the submesoscale horizontal fluxes will be overestimated. ${ }^{3}$

Of course, the rescaled MLE streamfunction will not be oriented according to the unresolved submesoscale fronts. While the vertical fluxes will be correct, the horizontal fluxes will be approximated by being oriented to slump only the resolved fronts.

\subsubsection{MLE-induced Velocity and Timestep Limitation}

With the $\Delta s / L_{f}$ rescaling, the MLE-induced velocity will scale with resolution as $u^{*} \propto \Delta s / L_{f}$, and the Courant-Friedrichs-Lewy limit on the timestep size, $\Delta t<\Delta s / u^{*}$, becomes independent of $\Delta s$. Simply put, the timestep is limited as though the gridscale were $L_{f}$ instead of $\Delta s$. If $u^{*}$ were the timesteplimiting velocity this limitation would be untenable in coarse-resolution models, but in practice $u^{*}$ is smaller than other velocities in the model.

A number of limiters are presently employed to prevent excessively large $u^{*}$ for small $L_{f}$. 1) A minimum value of $L_{f}$ is used $\left(L_{f, \min }\right)$; in coarseresolution models $L_{f, \text { min }}$ has been tested in the 1 to $10 \mathrm{~km}$ range. 2) Fig. 2 shows that there is an upper limit to the scaling, so $\min \left[\Delta s, 1^{\circ}\right] / \max \left[L_{f}, L_{f, \min }\right]$ also constrains the scaleup associated with (12) in very coarse resolution models. 3) Some models also clip $|\Psi| \leq v_{\max } \Delta z$ (see Appendices A, C).

To test the sensitivity of setting $L_{f}=\max \left(N H /|f|, L_{f, \min }\right)$, an oceanonly simulation with Large and Yeager (2004) forcing of the POP model was

\footnotetext{
${ }^{3}$ In coarse resolution models, $\Psi$ may be large due to rescaling. However, the implied submesoscale horizontal fluxes are still very small, and are typically dominated by the mesoscale horizontal fluxes (see section 3.2.1).
} 
performed with $L_{f}=\max (N H /|f|, 5 \mathrm{~km})$ and $L_{f}=\max (N H /|f|, 1 \mathrm{~km})$. The high latitudes where $|f|$ is large are more strongly affected by the choice of cutoff. Both models were numerically stable, but the choice of $L_{f}=\max (N H /|f|, 5 \mathrm{~km})$ avoids values of MLE streamfunction larger than the Atlantic meridional overturning streamfunction. However, despite large MLE streamfunctions, MLE horizontal heat fluxes and realistic vertical fluxes remained realistically bounded regardless of $L_{f, \min }$ (Section 3.2.1). Observations (Ferrari and Rudnick, 2000; Hosegood et al., 2006) and high-resolution simulations (Capet et al., 2008b) reveal that often the mixed layer frontal scale is much smaller than $5 \mathrm{~km}$, and $L_{f, \text { min }}$ as small as $200 \mathrm{~m}$ has been used successfully (Section 2.1.5).

Just after strong mixing $N$ may be close to zero in coarse-resolution models, making for a large scaleup $\Delta s /(N H / f)$. However, Rossby adjustment of fronts in the mixed layer is expected to precede or coincide with MLE restratification (Boccaletti et al., 2007), which restratifies to an expected end result of $N^{2} f^{2}=\left|\nabla_{H} \bar{b}^{z}\right|^{2}$ (Tandon and Garrett, 1994). A similar scaling results after symmetric instability restratification (Taylor and Ferrari, 2009). Simulations of initially unbalanced fronts reveal that the post-Rossbyadjusted state better predicts the MLI scales than using the unbalanced $N$ before Rossby adjustment (Boccaletti et al., 2007). Thus, the $N$ used for the resolution scaleup should never be smaller than the post-adjustment value. Because horizontal gradients are likely to be more robust than vertical gradients within the modeled mixed layer, thus the models here assume that this lengthscale also limits $L_{f}$, so

$$
L_{f}=\max \left(N H /|f|,\left|\nabla_{H} \bar{b}^{z}\right| H / f^{2}, L_{f, \text { min }}\right) .
$$

4

The buoyancy frequency, $N$, in the mixed layer is highly sensitive to other parameterization choices (e.g., maximum diffusivity of boundary layer mixing), thus the $L_{f, \text { min }}$ cutoff ought to be tuned along with other model parameters. Ideally, the $L_{f, \text { min }}$ cutoff for safe integration should decrease, along with model sensitivity to it, as resolution and confidence in mixed layer properties increases.

At present, model solutions remain artificially sensitive to the cutoff

\footnotetext{
${ }^{4}$ Since the resolved $\left|\nabla_{H} \bar{b}^{z}\right|$ is used, an enhancement of $\sqrt{\Delta s / L_{f}}$ could be argued. However, the limiter is required only when $N$ is unrealistic, as will be $L_{f}$.
} 
lengthscale $L_{f, \min }$. A $1 \mathrm{~km}$ cutoff in an ocean-only simulation of POP allows a ML depth nearly $20 \%$ shallower in high latitudes than a $5 \mathrm{~km}$ cutoff, for a $5 \mathrm{~m}$ shallower global-mean mixed layer depth (nearly doubling the $5.8 \mathrm{~m}$ difference between an MLE parameterization simulation and its control in Section 3). The requirement for tuning $L_{f, \min }$ is a consequence of overly coarse $\Delta s$ that becomes unnecessary with finer $\Delta s$, and the sensitivity and comparison to data in Section 3 should be held in light of the conservative choice of $5 \mathrm{~km}$ used in the models here. Section 2.1.5 proves that smaller values of $L_{f, \min }$ are possible in mesoscale-resolving simulations.

\subsubsection{High-Resolution Usage}

A serendipitous feature of the $\Delta s / L_{f}$ scaling is that it automatically handles regional variations of eddy scales in a high resolution model. In such a model $L_{f}$ may be resolved in some regions-e.g., where the mixed layer is particularly deep after deep convection-and not in other regions. However, (12) ensures that as resolution increases, the parameterization does less and less. An unresolved front (e.g., where $5 L_{f}=\Delta s$ ) has a scaled-up parameterization to account for underestimated buoyancy gradients. A justresolved front (where $L_{f}=\Delta s$ ) has no scale-up and reproduces the singlefront scaling validated by Fox-Kemper et al. (2008b) but still has insufficient resolution for MLI growth. A resolved front with MLEs permitted but not resolved $\left(L_{f}=4 \Delta s\right)$ is boosted by the parameterization, and a well resolved feature $\left(L_{f}=20 \Delta s\right)$ has negligible parameterized fluxes.

The present generation of mesoscale-eddy-resolving models at $O(10 \mathrm{~km})$ do not permit submesoscale eddies, which are permitted at $O(1 \mathrm{~km})$ resolution and resolved only when $\Delta s \leq O(H)$. Thus, the MLE parameterization should be used in $O\left(0.1^{\circ}\right)$ mesoscale models as well as in $O\left(1^{\circ}\right)$ ocean climate models. To verify that the MLE parameterization is stable in mesoscalerich models, and that $L_{f, \min }$ may be substantially reduced in that case, a preliminary $O\left(0.1^{\circ}\right)$ global POP ocean model with Large and Yeager (2004) forcing was executed including the MLE parameterization, hereafter POP$\mathrm{HI}^{ \pm}$.

The change in mixed layer depth after 5 days in the POP-HI ${ }^{+}$model is similar in magnitude to that observed in longer coarse-resolution simulations in Section 3. Interestingly, the location of fronts formed by straining between resolved mesoscale eddies selects the location of MLE restratification, just as expected from idealized simulations (Fox-Kemper et al., 2008b; Mahadevan et al., 2010). The $\Delta s / L_{f}$ scaling handles the issues of partial 
resolution of the mesoscale fronts without alteration. In models that do not have any mesoscale features, none of the relevant fronts are directly resolved, the timestep is long, the degree of rescaling by $\Delta s / L_{f}$ is large, and thus large $L_{f, \min }$ values are needed to guarantee stability. In the mesoscale-rich simulation, the limitation on frontal scale is minimal: $L_{f, \min }=200 \mathrm{~m}$ was used and this value limited $L_{f}$ less often. No timestep reduction was required as MLE-induced velocities are not the timestep-limiting process (the global maximum MLE-induced velocity including the scaleup factor is only $0.25 \mathrm{~m} / \mathrm{s}$ ), and the fronts from which MLEs form require an order of magnitude less strengthening by $\Delta s / L_{f}$ rescaling than in coarse-resolution models.

\subsection{Tracers other than buoyancy}

All of the models here use the MLE-induced overturning streamfunction to advect all tracers, not just buoyancy. This application relies on assumptions about the other tracer fields that should be mentioned. It is clear that other tracers will be affected by MLE restratification, and in the case of a resolved overturning front tracer gradients will also be overturned by $\Psi$. Thus, in a mesoscale-rich simulation, use of $\boldsymbol{\Psi}$ for all tracers is clearly warranted. However, the rescaling by $\Delta s / L_{f}$ to coarser models requires other statistical connections between the tracers and buoyancy.

In order for $\left\langle\overline{w^{\prime} c^{\prime}}\right\rangle \propto \hat{\mathbf{z}}\left\langle\left|\nabla \bar{b}^{z} \cdot \nabla \bar{c}^{z}\right|\right\rangle \Delta s / L_{f}$ to be resolution-independent, the cross-spectrum of tracer and density must be examined in addition to the buoyancy spectrum. To result in a similar resolution dependence, the co-spectrum ${ }^{5}$ of tracer concentration $(c)$ and buoyancy must also scale as $k^{-2}$ just as $\left\langle\overline{w^{\prime} b^{\prime}}\right\rangle \propto\left\langle\left|\nabla_{H} \bar{b}^{z}\right|^{2}\right\rangle \Delta s / L_{f}$ relies on a buoyancy spectral slope near $k^{-2}$. So, the buoyancy spectrum must scale as as $k^{-2}$, and so must also the tracer concentration spectrum and the co-spectrum. Fortunately, the $k^{-2}$ spectral scaling is an indication of the ubiquitous fronts of the near-surface ocean which stir and strain all surface tracers (Capet et al., 2008c).

Observations give some indication of the behavior of salinity $(S)$ and potential temperature $(\theta)$. Co-spectra of these tracers with buoyancy tend to have the same slope as the tracer and buoyancy spectra individually (Fig. 1),

\footnotetext{
${ }^{5}$ The co-spectrum is the real, concident-phase, part of the cross-spectral density function, and its integral over all wavenumbers is the zero-lag cross-correlation. The imaginary part, or quadrature spectrum, is not relevant to the correlation sought here. See Emery and Thomson (2001) for a detailed discussion.
} 
consistent with a uniform degree of density compensation across scales (Ferrari and Rudnick, 2000).

Generally, tracers that begin co-aligned with density will tend to stay aligned during straining for consistent co-spectral scaling. Thus, if stirring and frontogenesis dominate other processes such as external forcing, biology, radioactive decay, and chemical reactions these relationships will naturally arise for all tracers. This behavior has been observed for salinity and temperature (e.g., Ferrari and Rudnick, 2000), as well as other tracers under stirring-dominated conditions (e.g., chlorophyll: Strass, 1992). However, when a reaction or biological timescale rivals the stirring timescale, other scalings may result consistent with biological 'patchiness' (Strass, 1992; Mahadevan and Campbell, 2002; Tzella and Haynes, 2007).

The MLE-induced overturning only represents the mean transport averaged over many MLEs. Processes whereby tracer concentration reacts within a submesoscale feature based on peak concentration or scale-selectivity will be mis-estimated (e.g.,, submesoscale phytoplankton blooms: Spall and Richards, 2000). Furthermore, the scale selectivity of such processes is likely to affect the co-spectral slope, invalidating the resolution-independence of $\left\langle\overline{w^{\prime} c^{\prime}}\right\rangle$. However, sometimes conserved combinations of reacting species may be consistent with the rescaling while individual species may not, such as total nitrogen instead of planktonic nitrogen in an NPZ model (e.g., Franks, 2002).

Mesoscale eddy parameterizations include an additional effect for tracers other than buoyancy in addition to the Gent and McWilliams (1990) overturning streamfunction which is the mesoscale analog to the MLE streamfunction in (6). Redi (1982) diffusion adds isoneutral eddy fluxes of salinity, potential temperature, spice, etc., but does not affect buoyancy. Isoneutral tracer diffusion is neglected in present MLE parameterizations, as MLEinduced horizontal tracer fluxes are usually negligible when compared to mesoscale-eddy-induced horizontal fluxes (Fox-Kemper et al., 2008b). Since present near-boundary schemes include these mesoscale along-isopyncal diffusivities throughout the mixed layer (Treguier et al., 1997; Ferrari et al., 2008b, 2010), the Redi-like diffusion of tracers by MLEs would be negligible in coarse-resolution models. In future front- but not MLE-resolving, models the contribution may be noticeable, as indeed it is when mesoscale fluxes are absent in coastal environments (Capet et al., 2008a). Indeed, the MLE streamfunction (6) produces accurate vertical buoyancy fluxes (Section 2.1) at the expense of accurate horizontal buoyancy fluxes precisely because MLE 
horizontal fluxes are expected to be negligible. Neglecting the Redi-like diffusion of tracers by MLEs in coarse-resolution models is a consistent approximation.

\subsection{Approaching the Equator: Letting Gravity Slump Fronts}

The division by $|f|$ in the scaling for (5) for $\boldsymbol{\Psi}_{0}$ precludes its use in a global ocean model. Boccaletti et al. (2007) and Fox-Kemper et al. (2008b) demonstrate that MLEs are nearly geostrophic and thus care is required near the equator. Indeed the scaling (5) was based on simulation results where $f>0$ exclusively.

The interplay of mixing and MLI growth may be considered by timescale. Boccaletti et al. (2007) show that under typical midlatitude situations, the growth of instabilities given by (4) rivals the timescales of mixing events and the eddy fluxes are only intermittently interrupted. Fox-Kemper et al. (2008b) show that in the case of diurnal mixing in the extratropics, the same streamfunction scaling (5) applies in between mixing events with essentially the same magnitude as in the absence of mixing events, but typical mixing magnitudes greatly exceed the MLE restratification rate during mixing events. Thus, the MLE scaling in (5) may be used throughout the extratropics, with MLE restratification subsumed by episodic diapycnal mixing.

The MLE scaling (5) specifies an ageostrophic overturning in terms of the resolved buoyancy field. Other ageostrophic slumping may add to or inhibit the MLE overturning, such as Rossby adjustment, gravitational, frictional, frontogenetic, and wind-driven overturning (Tandon and Garrett, 1994; Ferrari and Young, 1997; Thomas and Ferrari, 2008; Mahadevan et al., 2010). As the equator is approached, the slumping by MLEs in (5) becomes rapid, yet the timescale for eddy growth increases (4). Thus, it is expected that direct frictional slumping of the front may be more rapid than waiting for the MLIs to reach finite amplitude. The solution for a frictionally-constrained slumping of an isopycnal in a rotating or nonrotating frame is (Young, 1994; Hallberg, 2003):

$$
\boldsymbol{\Psi}=\frac{H^{2} \nabla \bar{b}^{z} \times \hat{\mathbf{z}}}{\tau\left(f^{2}+\tau^{-2}\right)} \max \left\{0,\left[1-\left(\frac{2 z}{H}+1\right)^{2}\right]\right) .
$$

Aside from a slightly different $\mu(z)$, (14) differs from (6) by a factor of

$$
\frac{C_{e}^{-1}}{\tau \sqrt{f^{2}+\tau^{-2}}}=\frac{C_{e}^{-1}}{1+\tau^{2} f^{2} / 2+O\left(\tau^{4} f^{4}\right)}
$$


Thus, (14) and (6) are proportional in the small $f$ limit, but differ away from the equator where (6) converges to the extratropical MLE overturning in (5). ${ }^{6}$ This behavior is intended so that (6) provides nearly frictionless MLE overturning away from the equator but agrees with frictional, nonrotating overturning (14) near the equator. In contrast, the Young (1994) frictional scaling (14) remains constrained by friction even far from the equator. Consistently, extratropical simulations in Fox-Kemper et al. (2008b) show only a weak dependence on friction and Ekman number $\left(\Psi \propto \mathrm{Ek}^{-0.2}\right)$, while (14) is strongly frictional away from the equator with $\Psi \propto \mathrm{Ek}^{-1}$.

Ferrari and Young (1997) consider many methods for mixing the mixed layer (i.e., Newtonian relaxation, vertical viscosity \& diffusivity, sporadic mixing) each with different timescales. Given this uncertainty, a precise connection from $\tau$ in (6) to first principles is left unspecified here. Furthermore, the factor of $C_{e}$ in (15) is to be absorbed into $\tau$. Thus, $\tau$ is a timescale constant related to frictional processes, but intended to be tuned rather than determined by a priori estimates. Choosing a frictional equatorial limit for (6) regularizes $\Psi$ at the equator, and makes (6) an analytic, nonsingular function.

The discussions of Young (1994) and Ferrari and Young (1997) highlight horizontal shear dispersion and tracer flux associated with repeating slumping and vertical mixing events. Under the MLE parameterization, shear dispersion is not produced by (14) alone. The repeated slumping and mixing leading to shear dispersion is approximated by using the MLE parameterized overturning in conjunction with boundary layer mixing.

\subsection{Other Considerations}

\subsubsection{Mixing Layer versus Mixed Layer}

The formulation of Fox-Kemper et al. (2008b) uses mixed layer depth $H$, rather than the mixing layer or boundary layer depth. The scale $H$ is clearly the relevant one in MLE-resolving simulations. For example, in simulations featuring a diurnal cycle in Fox-Kemper et al. (2008b) the MLEs fill the mixed layer and restratify all of it, despite the fact that daytime mixing layer is much shallower than the mixed layer; only nighttime mixing penetrates to the mixed layer base. Some MLE implementations have used

\footnotetext{
${ }^{6}$ It is assumed that $\tau$ is greater than a day, which is typical based on the different estimates of (Ferrari and Young, 1997).
} 
boundary layer depth as $H$, because boundary layer mixing schemes such as KPP provide it (K-Profile Parameterization: Large et al., 1994). ${ }^{7}$ While mixing and mixed layer depths are often comparable, there is an important physical effect missing when mixing layer depth is used for $H$ in the MLE restratification. MLE restratification should restratify below the mixing layer and thus reduce the mixed layer depth systematically toward mixing layer depth.

There are many different definitions of mixed layer depth. The relevant mixed layer depth for the mixed layer eddies is one detailing where high stratification and low potential vorticity begin (i.e., a density difference or stratification criterion). Even among density-characterized mixed layers, there are still many definitions. Thus, the mixed layer depth used should be reported as part of the MLE implementation and is in the appendices here.

\subsubsection{Effects of Diapycnal Mixing}

Fox-Kemper et al. (2008b) and Haine and Marshall (1998) show that strong MLEs are robust in the face of moderate mixing due to cooling. However, when MLEs are weak, it is possible that their growth is interrupted altogether by the effects of turbulent mixing. This limit typically occurs when $\boldsymbol{\Psi}$ negligibly contributes to the mixed layer budget. Thus, the effects of the MLE parameterization will be small, so no changes are needed. Some observations suggest that MLE restratification occurs even during active mixing (Inoue et al., 2009), and symmetric instability restratification is expected during strong convection (Taylor and Ferrari, 2010).

\subsubsection{Adjustable Parameters}

The scaling (5) has the simulation-based parameter $C_{e} \approx 0.06$. This constant is an efficiency factor of MLEs that is validated against idealized simulations and should not be adjusted. However, the global model implementation (6) introduces two new parameters $L_{f}$ and $\tau$. These parameters are not presently well-constrained by observations, theory, or simulations. They may be tuned to reduce model bias.

Section 2.1.3 defines $L_{f}$ as a frontal width and Hosegood et al. (2006) suggest $L_{f}$ is close to the mixed layer deformation radius $N H / f$. However, because $\Delta s /(N H / f)$, it is prudent to specify a cutoff $L_{f, \min }$ (Section 2.1.4).

\footnotetext{
${ }^{7}$ Here, only the $\mathrm{CM} 2 \mathrm{G}^{+}$model uses boundary layer depth as $H$ for the submesoscale mixing. The depth is determined by energetic considerations (Appendix $\mathrm{C}$ )
} 
This cutoff values from $200 \mathrm{~m}-10 \mathrm{~km}$ have integrated stably. The smaller this artificial cutoff value is the more often the physical scale is used. $L_{f, \min }$ is most active near the poles where $N H / f$ is small, so polar mixed layer bias may govern the choice of its value.

The mixing timescale $\tau$ is likewise uncertain at present (Section 2.3). It is estimated to be in the 1-20day range (Section 2.3). Since the mixing timescale is used when $1 / f$ is large, $\tau$ may be chosen based on near-equatorial mixed layer bias.

\section{Parameterization Impact in Global Climate Simulations}

The MLE parameterization (6) substantially changes the mixed layer balance in general circulation models with realistic forcing. An ocean-only model forced with normal year forcing (Large and Yeager, 2004) shows a systematic reduction in mixed layer depth. Coupled Earth system models (CCSM3.5, $\mathrm{CM} 2 \mathrm{M} \alpha, \mathrm{CM} 2 \mathrm{G} \alpha$ ) have a more complex response, indicating that air-sea and ice-sea feedbacks are triggered by the introduction of the MLE parameterization.

This section presents the obvious direct and indirect impacts of the parameterization by way of four test simulations using the parameterization (denoted with $\mathrm{a}+$ ) versus four otherwise identical control simulations (denoted with a -). NY $/ \mathrm{POP}^{+}$and $\mathrm{NY} / \mathrm{POP}^{-}$are two 272-year integrations of the ocean-only POP model (Smith and Gent, 2004b) forced with Large and Yeager (2004) 'normal year' forcing. $\mathrm{CCSM}^{ \pm}$are two 172-year simulations of the NCAR CCSM3.5 Earth system model (Neale et al., 2008; Gent et al., 2009). CM2G $\alpha^{ \pm}$are two 100-year simulations based on the GFDL CM2G $\alpha$ Earth system model (Adcroft and Hallberg, 2006). CM2M $\alpha^{ \pm}$are two 300year simulations based on the GFDL CM2M $\alpha$ Earth system model (Griffies, 2009). All coupled models are run in present day (i.e., constant 1990) conditions. As discussed in the appendices, each model is a preliminary version of those to be used for the Intergovernmental Panel on Climate Change Fifth Assessment Report simulations. Modest or insignificant changes, for example to transports through Drake Passage, Bering Strait, Gibraltar Strait, and the Indonesian Throughflow, as well as El Niño statistics, are not detailed here. The analysis here presents the first careful set of control versus MLEparameterizing simulations; it is likely that some of the impacts of the MLE restratification have yet to be fully appreciated. 


\subsection{Effects on Mixed Layer Depth}

The simplest measure of the MLE restratification is the change to mixed layer depth, and the simplest cases to understand are the ocean-only $\mathrm{NY} / \mathrm{POP}^{ \pm}$. The mixed layer depth in $\mathrm{NY} / \mathrm{POP}^{+}$is reduced almost everywhere by the introduction of the MLE parameterization (i.e., compared to $\mathrm{NY} / \mathrm{POP}^{-}$, Fig. 4, upper panels). This reduction is evidence of MLE restratification of the mixed layer, whereby mixing events penetrate less deeply. $\mathrm{NY} / \mathrm{POP}^{-}$has global mean mixed layer depth $5.8 \mathrm{~m}$ deeper than NY/POP ${ }^{+}(72 \mathrm{~m}$ vs. $66 \mathrm{~m})$, with seasonal variations from 3 to $9 \mathrm{~m}$. In some deep convection regions, the mixed layer depth is reduced by over a kilometer (Fig. 4).

The change in mixed layer depth from $\mathrm{CCSM}^{-}$to $\mathrm{CCSM}^{+}$has a similar pattern as the ocean-only cases $\mathrm{NY} / \mathrm{POP}^{ \pm}$(Fig. 4 lower vs. upper), but the coupled model is more sensitive. $\mathrm{CCSM}^{-}$has global mean mixed layer depth $7.2 \mathrm{~m}$ deeper than $\mathrm{CCSM}^{+}(69 \mathrm{~m}$ vs. $62 \mathrm{~m})$, which varies from 4 to $12 \mathrm{~m}$ over seasonal and synoptic timescales. ${ }^{8}$ The difference in mixed layer depth between $\mathrm{CCSM}^{ \pm}$is substantial-it is larger than the difference between models with and without active atmospheres $\left(\mathrm{CCSM}^{+}\right.$vs. NY $\left./ \mathrm{POP}^{+}\right)$. Thus, MLE restratification has a larger effect than modeled air-sea feedbacks on mixed layer depth. Feedbacks also allow for deeper mixed layers in some locations in $\mathrm{CCSM}^{+}$over $\mathrm{CCSM}^{-}$while mixed layers in $\mathrm{NY} / \mathrm{POP}^{+}$are almost always shallower than $\mathrm{NY} / \mathrm{POP}^{-}$. For example, North Atlantic deep convection in $\mathrm{CCSM}^{+}$is shifted eastward when compared to $\mathrm{CCSM}^{-}$(Fig. 4, lower left) resulting in deeper wintertime mixed layers in the eastern North Atlantic.

The mixed layer is not always actively mixing, so the mixing layer is generally shallower than the mixed layer. Nonetheless, the MLE parameterization has roughly the same impact on mixing layer depth as mixed layer depth in $\mathrm{NY} / \mathrm{POP}^{ \pm}$and $\mathrm{CCSM}^{ \pm}$. NY/POP ${ }^{-}$has global mean boundary/mixing layer depth $5.4 \mathrm{~m}$ deeper than $\mathrm{NY} / \mathrm{POP}^{+}$, and $\mathrm{CCSM}^{-}$is $6.6 \mathrm{~m}$ deeper than $\mathrm{CCSM}^{+}$.

Despite algorithmic similarities between the MOM and POP ocean models, the results are somewhat different in $\mathrm{CM} 2 \mathrm{M} \alpha^{ \pm}$, a coupled model that uses the MOM ocean model. Fig. 6 shows the sensitivity of $\mathrm{CM} 2 \mathrm{M} \alpha^{ \pm}$to introducing the parameterization. $\mathrm{CM} 2 \mathrm{M} \alpha^{ \pm}$has a greater sensitivity than

${ }^{8}$ Note that in $\mathrm{NY} / \mathrm{POP}^{ \pm}$the atmospheric forcing in the control and test simulations is similar (up to flux differences from the bulk formulation of boundary conditions), while the atmospheric conditions in $\mathrm{CCSM}^{ \pm}$differ completely. 

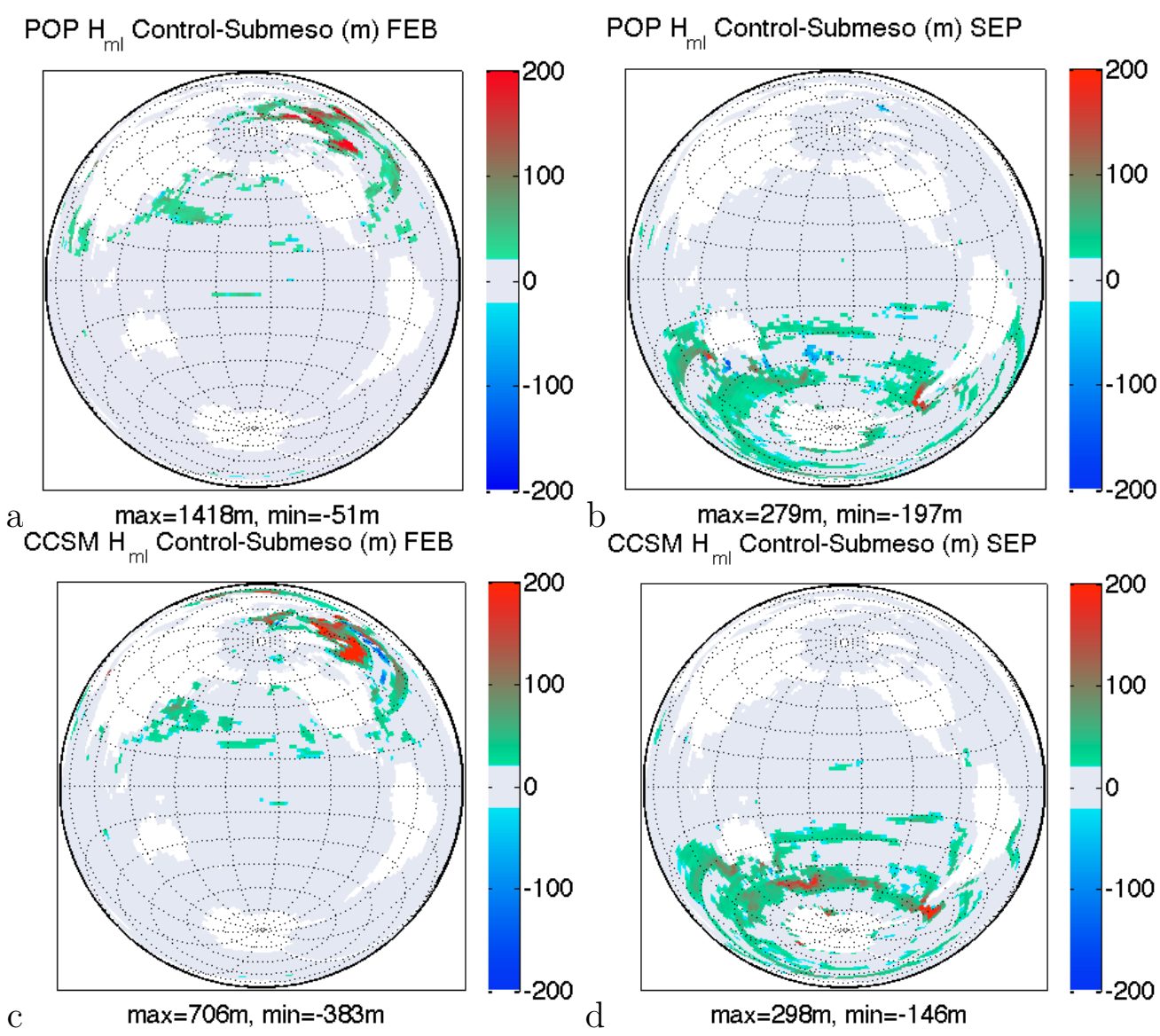

CCSM $\mathrm{H}_{\mathrm{ml}}$ Control-Submeso (m) SEP

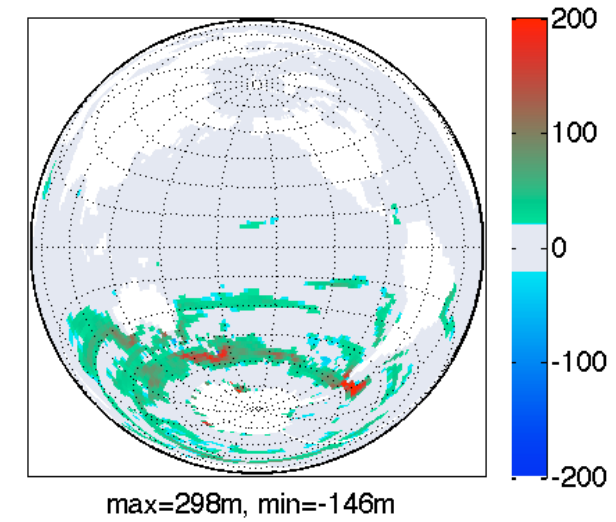

Figure 4: The reduction in mixed layer thickness from $\mathrm{NY} / \mathrm{POP}^{-}$to $\mathrm{NY} / \mathrm{POP}^{+}$in (a) February and (b) September and $\mathrm{CCSM}^{-}$to $\mathrm{CCSM}^{+}$in (c) February and (d) September. The MLE parameterization shoals mixed layers by design, although thicker mixed layers result regionally from feedbacks.

$\mathrm{CCSM}^{ \pm}$: the mean mixed layer depth in CM2M $\alpha^{+}$is $56 \mathrm{~m}$ and $\mathrm{CM} 2 \mathrm{M} \alpha^{-}$is $69 \mathrm{~m}$. It is unclear how much of the difference between $\mathrm{CCSM}^{+}$and $\mathrm{CM} 2 \mathrm{M} \alpha^{+}$ may be attributed to the different atmosphere, ocean, and cryosphere models coupled in these climate simulations.

The CM2 $\mathrm{G}^{ \pm}$models have a different boundary layer mixing scheme than the other models, which all use KPP. The CM2 $\mathrm{G}^{ \pm}$mixed layer is based on multi-layer bulk formulations (Hallberg, 2003). Nonetheless, it is compatible with the MLE parameterization (see Appendix C for implementation), and 
it shows similar patterns of mixing layer reduction with the MLE parameterization, but with a smaller magnitude than in the other models. CM2G $\alpha^{+}$ global mean mixing layer depth is $32.4 \mathrm{~m}, \mathrm{CM} 2 \mathrm{G} \alpha^{-}$is $31.2 \mathrm{~m}$. The sensitivity in $\mathrm{CM} 2 \mathrm{G} \alpha^{ \pm}$is roughly $1 / 5$ that of the 5 to $7 \mathrm{~m}$ changes to mixing layer depth in $\mathrm{NY} / \mathrm{POP}^{ \pm}, \mathrm{CCSM}^{ \pm}$, and $\mathrm{CM} 2 \mathrm{M} \alpha^{ \pm}$. Much of this reduced sensitivity is likely due to using the mixing layer depth rather than mixed layer depth as $H$ (see Appendix C). Since the mixing layer depth is usually shallower than mixed layer depth and (5) goes as $H^{2}$, a reduction of parameterized MLE effects is expected. Due to the minor MLE effects in CM2G $\alpha^{ \pm}$, these model simulations will be discussed in less detail than the others.

\subsubsection{Comparison to Mixed Layer Depth Climatologies}

The mixed layer depths are defined based on density criteria in all of the models. They are compared with the density-criterion mixed layer depth $\left(\Delta \sigma_{\theta}=0.03 \mathrm{kgm}^{-3}\right)$ from the mixed layer depth climatology of de Boyer Montégut et al. (2004, updated to include ARGO float data to September, 2008). CM2M $\alpha^{ \pm}$uses the same criterion as this climatology, but NY/POP ${ }^{ \pm}$ and $\mathrm{CCSM}^{ \pm}$use a gradient density criterion rather than a density difference from surface density criterion. These different definitions may be important prognostically as density anomalies are worked on by boundary mixing and MLE restratification, but they generally agree diagnostically to an accuracy where differences due to different density-criteria are dwarfed by the model biases observed here (Fox-Kemper et al., 2008b). Similarly, comparison to other climatologies (alternate definitions of de Boyer Montégut et al., 2004; Monterey and Levitus, 1997; Dong et al., 2008) yield sufficiently similar results that other climatologies are not presented.

Fig. 5 compares the $\mathrm{CCSM}^{+}$and $\mathrm{CCSM}^{-}$to the mixed layer depth climatology. There are fewer deep-biased regions in $\mathrm{CCSM}^{+}$than $\mathrm{CCSM}^{-}$which indicates that deeper-than-climatology mixed layers are being reduced by the MLE parameterization. The bottom row of figures shows the probability model of mixed layer depth interpolated onto the climatology grid having a particular bias against the climatology. $\mathrm{CCSM}^{+}$(black, solid line) is more likely to have near zero bias than $\mathrm{CCSM}^{-}$(red, dashed line). Increased zerobias probability results from decreased deep-bias probability. The probability of shallow mixed layer bias is increased slightly. The upper and middle panels of Fig. 5 show that the MLE parameterization mostly affects deep mixed layers as (6) predicts. However, the MLE restratification acts on shallow mixed layers as well: the bias scaled relative to the local mixed layer depth (bottom 
right) shows a similar bias reduction pattern. Overall, the averaged bias over the histogram in Fig. 5 is $9 \mathrm{~m}$ for $\mathrm{CCSM}^{-}$and $1 \mathrm{~m}$ for $\mathrm{CCSM}^{+}$. Likewise, the mean bias in $\mathrm{NY} / \mathrm{POP}^{-}$is $10 \mathrm{~m}$ and $4 \mathrm{~m}$ for $\mathrm{NY} / \mathrm{POP}^{+}$.

Fig. 6 shows similar but more pronounced effects in the CM2M $\alpha^{ \pm}$comparison. The bias reduction here is large, but the peak of the probability distribution in both $\mathrm{CM} 2 \mathrm{M} \alpha^{+}$and $\mathrm{CM} 2 \mathrm{M} \alpha^{-}$is too shallow. Thus, the mean bias of CM2M $\alpha^{-}$is only $0.2 \mathrm{~m}$, while the mean bias of CM2M $\alpha^{+}$is $-2.5 \mathrm{~m}$. It is likely that strengthening the boundary layer mixing is warranted in $\mathrm{CM} 2 \mathrm{M} \alpha^{+}$. Bias reduction when implementing the MLE parameterization is desirable, but it is not a clear indication of accurate MLE parameterization physics. The boundary layer mixing and other subgrid parameters were tuned before the introduction of the MLE parameterization. Much larger bias reduction may result from full tuning with the MLE parameterization in place. The MLE restratification in (6) is not simply related to the boundary layer mixing scheme, so the different sensitivities may reveal better parameter choices. It is clear that the peak of the histogram in Fig. 6 is larger in $\mathrm{CM} 2 \mathrm{M} \alpha^{+}$than $\mathrm{CM} 2 \mathrm{M} \alpha^{-}$, only its location needs to move toward deeper mixed layers.

The MLE parameterization reduced bias in $\mathrm{CCSM}^{+}$and NY/POP ${ }^{+}$and enlarged the near-zero bias peak of the histogram in $\mathrm{CM} 2 \mathrm{M} \alpha^{+}$. However, persistent errors remain, which are likely signs of other misrepresented physical processes. The location of North Atlantic deep convection remains poor in all models, and the Southern ocean mixed layer is too shallow. Future developments, for example in overflow parameterizations (Danabasoglu et al., 2010) and Langmuir mixing (Webb et al., 2010), may alleviate these persistent biases.

\subsection{Meridional Overturning Circulation}

The global Meridional Overturning Circulation, or MOC, is affected by the MLE parameterization. There are two aspects of MLE impact: the direct effect of the parameterized MLE overturning itself and the indirect effects of MLE restratification, which affects the mean and variability of the resolved, Eulerian and mesoscale-eddy induced circulation.

\subsubsection{Direct: Magnitude of the MLE Meridional Overturning}

The overturning due to the MLE parameterization can be substantial, with $10 \mathrm{~Sv}$ or more global meridional overturning in $\mathrm{CM} 2 \mathrm{M} \alpha^{+}$and $\mathrm{CCSM}^{+}$ 
(Fig. 7). Thus, the parameterization overturns nearly as much fluid volume as the deeper North Atlantic overturning circulation. However, the submesoscale overturning occurs exclusively within the mixed layer where vertical gradients are small so there is little MLE horizontal transport (recall $\left.\overline{v^{\prime} c^{\prime}} \propto \Psi \partial \bar{c} / \partial z\right)$. The Gent and McWilliams (1990) mesoscale overturning acts in the thermocline, where vertical gradients are large so horizontal tracers transports are large. Fox-Kemper et al. (2008b) and Capet et al. (2008a) emphasize that the submesoscale should dominate the mesoscale in vertical fluxes due to the small aspect ratio and large Rossby number of submesoscale features, but be subdominant in horizontal fluxes due to the larger scale and higher energy of mesoscale features. The MLE parameterization mimics this behavior, providing vertical heat fluxes an order of magnitude larger than the mesoscale, and horizontal fluxes an order of magnitude smaller than the mesoscale. For example, the submesoscale meridional heat transport associated with the overturning in (Fig. 7) is less than 0.01PW. Generally, the horizontal heat transport by the MLE parameterizations is more than an order of magnitude smaller than the Eulerian meridional heat transport and an order of magnitude smaller than depth-integrated mesoscale horizontal fluxes. These results are consistent across all the models tested.

Well-resolved MLEs do not overturn such a large quantity of fluid, however, the MLE parameterization does. Coarse resolution combines many narrow but strong subgridscale fronts into weak gradients across coarse gridpoints. The $\Delta s / L_{f}$ rescaling (Section 2.1) recovers the average magnitude of the vertical buoyancy and tracer fluxes $\left\langle\overline{w^{\prime} b^{\prime}}\right\rangle$, but the overturning features unrealistically large in horizontal scale and carry more volume to do so. Thus, the overturning streamfunction is less useful in measuring the MLE effects than other metrics, for example the MLE vertical heat fluxes versus other vertical heat fluxes within the mixed layer (see Fox-Kemper et al., 2008b, for an example).

\subsubsection{Indirect: $M O C$ Transports}

In addition to the MLE overturning streamfunction, the deep meridional volume overturning is substantially affected in some regions by changes induced by MLE restratification. The MOC is strengthened near $45 \mathrm{~N}$ when the MLE parameterization is used, indicating more overturning of North Atlantic Deep Water. The maximum Atlantic MOC is about $1.5 \mathrm{~Sv}$ weaker in $\mathrm{NY} / \mathrm{POP}^{-}$than $\mathrm{NY} / \mathrm{POP}^{+}, 1.5 \mathrm{~Sv}$ weaker in $\mathrm{CCSM}^{-}$than $\mathrm{CCSM}^{+}$, and 2Sv weaker in $\mathrm{CM} 2 \mathrm{M} \alpha^{-}$than $\mathrm{CM} 2 \mathrm{M} \alpha^{+}$. This strengthening covers limited 
meridional extent near $45 \mathrm{~N}$, and supports a northward shift in the boundary between the subtropical and subpolar waters. From $30 \mathrm{~N}$ to the equator overturning is weakened slightly or not at all, depending on the model. Northward heat transport is slightly affected worldwide $(<10 \%)$, but the models disagree as to whether MLE restratification increases or decreases the total heat transport and the effect tends to be spatially variable. The overturning in the Southern Ocean is not consistently affected across the models.

This strengthening of the deep overturning near $45 \mathrm{~N}$ is unintuitive, since it is often assumed that decreased ventilation (by the MLE restratification) will decrease the rate of overturning. However, the MLE parameterization increases overturning while decreasing ventilation. For example, the ideal age of North Atlantic Deep Water (NADW) is about 20yr older at 500-1000m depths in all of the models with MLE restratification than their control runs, but the MOC is about $10 \%$ stronger. So, NADW is older, but MOC overturning is stronger. Yeager and Jochum (2009) perform a detailed analysis of how changes to the location of modeled deep convection and surface buoyancy fluxes can affect the magnitude and location of the MOC transport. The simulations here show generally shallower convection and convection in different locations, as well as heat fluxes changes of $\mathrm{O}\left(50 \mathrm{~W} / \mathrm{m}^{2}\right)$ across the Labrador, Irminger, Greenland-Iceland-Nordic (GIN) seas and North Atlantic. While the location of deep convection remains unrealistic in comparison to observations, tracers indicate that these changes in modeled North Atlantic Deep Water are an improvement (Section 3.3).

\subsubsection{Indirect: $A M O C$ variability in $\mathrm{CM} 2 \mathrm{M} \alpha^{ \pm}$}

Variability of the Atlantic Meridional Overturning Circulation (AMOC) is a topic of present interest due to its impact on Atlantic climate. We illustrate here one important potential effect of the MLE restratification on AMOC variability. Critical elements in this discussion are how the models transition their implementation of the mesoscale parameterization of Gent and McWilliams (1990, GM90) from the quasi-adiabatic interior to the surface boundary layer and whether an overflow parameterization is present (Danabasoglu et al., 2010). These details affect how the mesoscale parameterization interacts with the submesoscale parameterization and what stratification is present during convection.

Fig. 8 exhibits time series for the AMOC index from CM2.1, CM2M $\alpha^{+}$, and $\mathrm{CM} 2 \mathrm{M}^{-}$. CM2.1 is an older version of a coupled climate model closely resembling $\mathrm{CM} 2 \mathrm{M} \alpha^{-}$. Both $\mathrm{CM} 2.1$ and $\mathrm{CM} 2 \mathrm{M} \alpha^{+}$show modest amplitude 
fluctuations of less than 2 Sv standard deviation (blue and red lines in Fig. 8), whereas $\mathrm{CM} 2 \mathrm{M} \alpha^{-}$exhibits far larger amplitude fluctuations of roughly $3 \mathrm{~Sv}$ standard deviation (green line, Fig. 8). It is beyond the scope of this paper to fully diagnose the cause of the fluctuations in CM2M $\alpha^{-}$, but they tend to occur during a relocation of the site of deep convection from the Labrador and Irminger Seas and North Atlantic to the GIN seas (Fig. 9). Curiously, Yeager and Jochum (2009) show that in a model similar to $\mathrm{CCSM}^{-}$, a relocation from Labrador sea convection to GIN sea convection decreases the AMOC. In $\mathrm{CM} 2 \mathrm{M} \alpha^{+}$, reduced AMOC variability coincides with reduced variability in convection, as indicated by a reduction in the standard deviation of January and February mixed layer depth by 10-20\% averaged over the GIN seas and 40-50\% averaged over the Labrador Sea and North Atlantic deep convection area.

Apparently, this result is model-dependent. Improving Nordic Sea water mass properties, e.g., by overflow parameterizations (Danabasoglu et al., 2010), tends to reduce the sensitivity of AMOC variability (not shown). Also not all models without the MLE parameterization have as much variability as $\mathrm{CM} 2 \mathrm{M} \alpha^{-}$. As discussed in Appendix A, both CM2M $\alpha^{ \pm}$and $\mathrm{CCSM}^{ \pm}$employ the Ferrari et al. (2008a) mesoscale eddy scheme, whereas the older CM2.1 model (which does not use a MLE parameterization) is based on the Treguier et al. (1997) transitioning scheme. CM2.1 and $\mathrm{CCSM}^{-}$(Fig. 8) exhibit only modest fluctuations of a magnitude similar to $\mathrm{CM} 2 \mathrm{M} \alpha^{+}$. However, this behavior does not condemn the Ferrari et al. (2008a) scheme. CCSM ${ }^{-}$uses this scheme without excessive variability, and a newer model version resembling CM2M $\alpha^{-}$, but with the Ferrari et al. (2010) mesoscale eddy scheme, has variability as large as CM2M $\alpha^{-}$. Overall, MLE restratification tends to either indirectly stabilize or minimally affect AMOC variability, depending on details of modeled North Atlantic Deep Water formation.

\subsection{Affected Tracers: Temperature, Salinity, Ideal Age, and CFC-11}

The direct effects of the MLE parameterization on mixed layer depth leads to many indirect effects. Since the mixed layer depth bias was reduced, it seems logical that these changes will be beneficial to the validity of the model overall. Only the most notable of these effects are mentioned here.

Global mean temperature is affected by the MLE parameterization while global mean salinity is negligibly affected. $\mathrm{NY} / \mathrm{POP}^{-}$has global mean temperature $0.05 \mathrm{~K}$ warmer than $\mathrm{NY} / \mathrm{POP}^{+}$. Similarly, $\mathrm{CCSM}^{-}$is $0.06 \mathrm{~K}$ warmer 
than $\mathrm{CCSM}^{+}$, and $\mathrm{CM} 2 \mathrm{M} \alpha^{-}$is $0.1 \mathrm{~K}$ warmer than $\mathrm{CM} 2 \mathrm{M} \alpha^{+}$. In all the models, subsurface waters are cooled by the introduction of MLE restratification, with the greatest cooling occurring over $100-1000 \mathrm{~m}$ depths and nearly uniformly globally. On the other hand, sea surface temperatures are typically warmer by $\mathrm{O}(0.1 \mathrm{~K})$. The global mean temperature variations do not vary seasonally. Thus, this temperature change seems to be a result of increased stratification with the MLE parameterization. SST differences are locally modest, except in the North Atlantic where the aforementioned changes to deep convection location occur.

The global mean surface heat flux control versus MLE difference ranges from 0.1 to $0.15 \mathrm{~W} / \mathrm{m}^{2}$ among the models. While this is a small flux value compared to local fluxes, it is as large as the global air-sea flux imbalance after 300 years of model integration. In the North Atlantic region, $\mathrm{O}\left(50 \mathrm{~W} / \mathrm{m}^{2}\right)$ changes of both signs indicate relocation of deep convection. Elsewhere, the flux differences are smaller $\mathrm{O}\left(5 \mathrm{~W} / \mathrm{m}^{2}\right)$, but often significant (50\% of the world ocean area has a $15 \%$ or greater change in net surface flux). Models including MLE restratification have more mixed layer stratification, with increased sea surface temperature under the same mixed layer heat content, so surface fluxes tend to cool the ocean slightly more than without MLE restratification. Thus, MLE restratification tends to cool the ocean overall, but warm the sea surface temperature.

A more esoteric explanation for increased subsurface stratification with the MLE restratification concerns the potential vorticity of subducted water masses. Theory (e.g., Luyten et al., 1983; Marshall and Nurser, 1992) predicts conservation of mixed layer potential vorticity after subduction. If mixed layer potential vorticity is increased by MLE restratification, this change should imprint on the potential vorticity of subducted water masses, thereby increasing subsurface potential vorticity and stratification.

Decreased ventilation of subsurface waters tends to result in older subsurface water masses. $\mathrm{NY} / \mathrm{POP}^{-}$has global mean ideal age 0.3 yr younger than $\mathrm{NY} / \mathrm{POP}^{+}$(seasonally steady). $\mathrm{CCSM}^{-}$has global mean ideal age 0.6 yr younger than $\mathrm{CCSM}^{+}$(with seasonal variations). $\mathrm{CM} 2 \mathrm{M} \alpha^{-}$has global mean ideal age 2.6 yr younger than $\mathrm{CM} 2 \mathrm{M} \alpha^{+}$. In some locations the differences are large. For example, in CM2M $\alpha^{+}$and $\mathrm{CCSM}^{+}$North Atlantic Deep Water is 20 years older near its formation region at 500-1000m depth than in $\mathrm{CM} 2 \mathrm{M}^{-}$and $\mathrm{CCSM}^{-}$, and these water masses are typically less than 50 years old. Antarctic intermediate water is also made somewhat older by MLE restratification. 


\subsection{1. $C F C-11$}

The changes in surface temperatures and deep water ventilation will affect passive tracers. These effects can be studied by comparison of modeled chloroflurocarbon (CFC) concentrations in comparison to observations of CFCs. In general, the intermodel differences (e.g.,, $\mathrm{NY} / \mathrm{POP}^{-}$versus $\mathrm{CCSM}^{-}$) exceed the differences upon introduction of the MLE parameterization $\left(\mathrm{NY} / \mathrm{POP}^{+}\right.$versus $\left.\mathrm{NY} / \mathrm{POP}^{-}\right)$. Many of the changes to $\mathrm{CFC}-11$ concentrations are negligible or inconsequential in reducing bias versus the World Ocean Circulation Experiment sections, but there is a noticeable improvement in CFC-11 concentration in the North Atlantic. Fig. 10 shows that the $\mathrm{CCSM}^{-}$has too much CFC-11 in the water at depth in the eastern part of the Atlantic. This bias is alleviated in $\mathrm{CCSM}^{+} . \mathrm{NY} / \mathrm{POP}^{+}$and $\mathrm{CM} 2 \mathrm{M} \alpha^{+}$show similar improvement.

The North Atlantic column inventory is also affected. The CFC-11 column inventory bias versus GLODAP (Key et al., 2004) is overestimated in most $1^{\circ}$ models in the high-latitude North Atlantic. $\mathrm{NY} / \mathrm{POP}^{+}$brings the bias down by roughly $20 \%$ in this region. CFC-11 concentrations are still too high in $\mathrm{NY} / \mathrm{POP}^{+}$, but the bias is reduced. Further reductions in these biases are found when the MLE parameterization is combined with the overflow parameterization of Danabasoglu et al. (2010). Similar North Atlantic bias reduction occurs in $\mathrm{CM} 2 \mathrm{M}^{+}$and $\mathrm{CCSM}^{+}$.

\subsection{Changes to Sea Ice}

The MLE parameterization is expected to affect other components of the climate system that rely on ocean surface properties. The MLE parameterization has a large effect at high latitudes, and indeed sea ice is sensitive to the MLE parameterization.

In $\mathrm{CCSM}^{ \pm}$, the sea ice sensitivity is large, up to $50 \%$ of thickness in some areas, and robust over the last 70 years of the simulations. Total ice volume is similar between $\mathrm{CCSM}^{+}$and $\mathrm{CCSM}^{-}$, but $\mathrm{CCSM}^{+}$has more and thicker ice in the Labrador, Irminger, and Chukchi Seas, while $\mathrm{CCSM}^{-}$has more and thicker ice in the Barents and Beaufort Seas. Diagnosis of the sea ice heat budgets indicates that the redistribution of ice may be driven by variations in basal ice melt, but other feedbacks in the coupled model are likely to contribute. This effect seems connected to reduced mixed layer heat capacity when the MLE parameterization is used. As the MLE parameterization seems to reduce mixed layer depth bias, it is recommended that it be used for sea ice modeling studies. 
$\mathrm{CM} 2 \mathrm{M} \alpha^{ \pm}$shows similarly large sensitivity in sea ice thickness and extent. However, instead of a rearrangement of ice, there is generally an increase of ice extent and thickness throughout the polar region in CM2M $\alpha^{+}$ over $\mathrm{CM} 2 \mathrm{M} \alpha^{-}$. There is more summertime ice and less basal heat flux in wintertime in the $\mathrm{CM} 2 \mathrm{M} \alpha^{+}$simulation. It is unclear whether the differences between $\mathrm{CCSM}^{ \pm}$and $\mathrm{CM} 2 \mathrm{M} \alpha^{ \pm}$sea ice sensitivity is due to different sea ice packages or differences in model state.

\section{Conclusions}

The mixed layer eddy parameterization proposed by Fox-Kemper et al. (2008b) and validated initially by Fox-Kemper and Ferrari (2008) and FoxKemper et al. (2008a) are recommended for general use in present global climate models based on stability, minimal cost, and bias reduction. The mixed layer depth is generally shallower when the parameterization is used, and this effect increases the probability of zero bias in all models tested versus the recently updated climatology of de Boyer Montégut et al. (2004) which includes ARGO profiles to September, 2008.

The parameterization is modified from the form (5), as proposed by FoxKemper et al. (2008b), for inclusion in global models. The modified form (6) relies on the following: addition of a mixing timescale $\tau$ to handle behavior near the equator (see Section 2.3) and addition of a scaling factor $\Delta s / L_{f}$ to account for weaker density gradients in coarse resolution models (see Section 2.1). There are some remaining issues due to these changes, such as the optimal choice of the $\tau$ parameter, stabilizing the $\Delta s / L_{f}$ scaleup most sensibly, and what to do with tracers whose spectrum or co-spectrum with density is not consistent with a $k^{-2}$ scaling law. Future work will undoubtedly improve the present approach in these areas.

The parameterization has both direct and indirect effects: it plays a role in ice location and thickness, mixed layer stratification, surface fluxes, MOC strength, ventilation, and variability, but only a small role in horizontal tracer transport. As this parameterization has been validated against process models (Fox-Kemper and Ferrari, 2008), and the probability of mixed layer depth bias is reduced, it is anticipated these changes increase model fidelity.

Submesoscale effects other than MLEs also impact stratification, such as frontogenesis, front-wind interactions, and symmetric instabilities. Parameterization of these effects will challenge submesoscale investigators for some time to come. 


\section{Acknowledgments}

We thank members of the Climate Process Team (CPT) on Eddy -Mixed Layer Interaction for helpful discussion and interactions. This work was supported by the NSF Grants OCE-0612143, OCE-0612059, DMS-0855010, and OCE-0934737. The computational resources for $\mathrm{NY} / \mathrm{POP}^{ \pm}$and $\mathrm{CCSM}^{ \pm}$ integrations were provided by the Computational and Information Systems Laboratory of the National Center for Atmospheric Research (NCAR). NCAR is sponsored by the National Science Foundation. The computational resources for CM2M $\alpha^{ \pm}$and $\mathrm{CM} 2 \mathrm{G} \alpha^{ \pm}$integrations were provided by the NOAA Geophysical Fluid Dynamics Laboratory.

\section{Appendix A. CM2M $\alpha^{ \pm}$Simulation and Implementation}

The CM2M $\alpha^{-}$and $\mathrm{CM} 2 \mathrm{M} \alpha^{+}$simulations employ the MOM4p1 ocean code of Griffies (2009), coupled to the same atmosphere, land, and sea ice model as in the CM2.1 climate model (Griffies et al., 2005; Gnanadesikan et al., 2006; Delworth et al., 2006). We refer to the MOM4p1-based climate model as $\mathrm{CM} 2 \mathrm{M} \alpha$, and note that this is a preliminary version of the climate model CM2M that will be part of GFDL's contributions to the 5th IPCC assessment. All climatological fields from this model are taken from years 181-200 of a 300 year coupled climate simulation, where the radiative forcing is kept constant at 1990 values.

The ocean parameterizations in $\mathrm{CM} 2 \mathrm{M} \alpha$ have been extensively updated from those used in CM2.1, with documentation of these developments the subject of future publications. Of note for the present paper is an update to the transition of the GM90 scheme into the upper ocean boundary layer, which is here based on the scheme proposed by Ferrari et al. (2008a) and tested by Danabasoglu et al. (2008), whereas CM2.1 uses the methods described by Treguier et al. (1997). ${ }^{9}$ Implementation of the MLE parameterization follows that described in the present paper, with the following details noted.

- The front length $L_{f}$ is taken as the maximum of the mixed layer deformation radius $N H / f$, and $5 \mathrm{~km}$.

\footnotetext{
${ }^{9}$ Development subsequent to CM $2 \mathrm{M} \alpha$ led to the use of Ferrari et al. (2010) rather than Ferrari et al. (2008a) for CM2M.
} 
- The mixed layer depth is diagnosed as in Levitus (1982), where the depth represents an interpolation to find the first depth where the difference in buoyancy relative to the surface is greater than $0.0003 \mathrm{~m} \mathrm{~s}^{-2}$.

- The MLE parameterization is disabled in regions where the mixed layer depth is diagnosed to be less than four vertical model grid cells (nominally $40 \mathrm{~m}$ ), in order to ensure sufficient resolution to represent the vertical structure of the MLE streamfunction $\boldsymbol{\Psi}$.

- The MLE streamfunction $\Psi$ has a maximum magnitude at each grid cell given by $|\Psi| \leq V \Delta z$, where $V=0.5 \mathrm{~m} \mathrm{~s}^{-1}$ is a specified velocity scale, and $\Delta z$ is the vertical grid spacing. This ceiling ensures that the MLE streamfunction will not introduce spurious instabilities that may otherwise arise under extreme conditions, such as when the model is spinning up from rest.

- The MLE streamfunction $\boldsymbol{\Psi}$ is spatially smoothed in the horizontal using a 1-2-1 filter, which serves to reduce the amplitude of spurious grid scale noise that may otherwise appear in the numerical implementation of $\boldsymbol{\Psi}$ on the B-grid used by MOM. It should be noted that no such filter is used in $\mathrm{CCSM}^{+}$or $\mathrm{CM} 2 \mathrm{G} \alpha^{+}$, and that this filter will reduce $\nabla_{H} \bar{b}^{z}$ and thereby reduce the effect of the MLE parameterization.

\section{Appendix B. $\mathrm{CCSM}^{ \pm}$and NY $/ \mathrm{POP}^{ \pm}$Simulation and Implemen- tation}

The ocean component of the Community Climate System Model (CCSM) is a level-coordinate ocean model based on the Parallel Ocean Program (POP) of the Los Alamos National Laboratory (Smith and Gent, 2004a). The present ocean model version differs significantly from the one described in Danabasoglu et al. (2006) used in the CCSM3 simulations: the base code has been updated to POP2 and many physical and numerical developments have been incorporated. These improvements include the near-surface eddy flux parameterization of Ferrari et al. (2008a) as implemented by Danabasoglu et al. (2008), the abyssal tidal mixing parameterization of St Laurent et al. (2002) as implemented by Jayne (2009), and modified anisotropic horizontal viscosity coefficients with much lower magnitudes than in CCSM3 Jochum et al. (2008). The representation of the eddy fluxes in POP consists 
of an isopycnal diffusion Redi (1982) and a GM90 eddy-induced velocity represented as a skew flux (Griffies, 1998). In all the experiments, we use 600 $\mathrm{m}^{2} \mathrm{~s}^{-1}$ for both the isopycnal and thickness diffusivities except for tapering for numerical stability. Within the surface diabatic layer, the horizontal diffusivity coefficient is also set to the same value.

The MLE parameterization is implemented following the same discretization for the isopycnal diffusion and the GM90 scheme described in Griffies (1998). Below, we present a list of POP specific implementation details:

- Following Large et al. (1997), we calculate the mixed layer depth $H$ as the shallowest depth where the local, interpolated buoyancy gradient matches the maximum buoyancy gradient between the surface and any discrete depth within that water column.

- In our calculations of the front width $L_{f}$, we also consider a third length scale based on the horizontal gradients of buoyancy $M^{2}$. Thus, we calculate

$$
L_{f}=\max \left(\frac{M^{2} H}{f^{2}}, \frac{N H}{|f|}, L_{f, \text { min }}\right) .
$$

- We replace all occurrences of $f$, including in the above equation, by $f \rightarrow \sqrt{f^{2}+\tau^{-2}}$.

- The local grid scale of the coarse resolution model $\Delta s$ is evaluated using either $\Delta s=\min \left(\Delta x^{T}, L_{\max }\right)$ or $\Delta s=\min \left(\Delta y^{T}, L_{\max }\right)$ depending on the $\boldsymbol{\Psi}$ component. Here, $\Delta x^{T}$ and $\Delta y^{T}$ represent the grid lengths centered at the tracer grid points along the grid-zonal and grid-meridional directions, respectively. Also, we use $L_{\max }=111 \mathrm{~km}$, corresponding to about $1^{\circ}$.

- In our standard implementation, we set $C_{e}=0.07, \tau=86400 \mathrm{~s}$, and $L_{f, \min }=5 \mathrm{~km}$.

- No smoothing operators are applied on any of the variables involved in the MLE parameterization.

We use the nominal $1^{\circ}$ horizontal resolution version of the ocean model described in Danabasoglu et al. (2006). However, the number of vertical levels has been increased from 40 levels in CCSM3 to 60 levels in the present 
version. Most of this increase occurs in the upper-ocean where the resolution is uniform at $10 \mathrm{~m}$ in the upper $160 \mathrm{~m}$. The resolution increases to $250 \mathrm{~m}$ by a depth of about $3500 \mathrm{~m}$, below which it remains constant. The minimum and maximum ocean depths are 30 and $5500 \mathrm{~m}$, respectively.

In uncoupled ocean integrations, the surface fluxes of heat, salt, and momentum are computed using the bulk forcing method described in Large et al. (1997) and Large and Yeager (2004). We use the normal-year atmospheric forcing (NY) data sets developed by Large and Yeager (2004). This data set consists of single annual cycles of all the needed fields, and can be used repeatedly without initiating any spurious transients. It has been recently proposed as common atmospheric forcing data for use in global ocean and ocean-ice simulations, i.e., Coordinated Ocean-ice Reference Experiments (Griffies et al., 2009). A weak salinity restoring to the Polar Science Center Hydrographic Climatology (PHC2) data (a blending of Levitus et al., 1998; Steele et al., 2001) with a 4-year time scale over $50 \mathrm{~m}$ is applied globally with its global mean subtracted. We do not use an active sea-ice model in uncoupled ocean integrations. Instead, we prescribe sea-ice fraction using a daily observed data set from Comiso (1999). Further details of these forcing data sets and forcing formulation, including treatment of under-ice forcing and river runoff are found elsewhere (Large and Yeager, 2004; Danabasoglu et al., 2009).

The coupled simulations use the CCSM3.5 described in Gent et al. (2009) in its present-day, i.e., year 1990 forcing, conditions. In addition to the ocean model, the other components contain numerous improvements and updates. In particular, the atmospheric model is based on the nominal $2^{\circ}$ horizontal resolution, 26 vertical level, finite-volume dynamical core version of the Community Atmospheric Model detailed in Neale et al. (2008).

We performed four experiments. The $\mathrm{NY} / \mathrm{POP}^{+}$and $\mathrm{NY} / \mathrm{POP}^{-}$cases are the uncoupled ocean only simulations with and without the MLE parameterization, respectively. The corresponding coupled cases with and without the MLE parameterization are denoted as $\mathrm{CCSM}^{+}$and $\mathrm{CCSM}^{-}$, respectively. The uncoupled and coupled experiments are integrated for 272 and 172 years, respectively, starting with the PHC2 January-mean potential temperature and salinity climatology and zero velocity. Two additional 100-year uncoupled simulations were performed with $L_{f, \min }$ set to 1 and $5 \mathrm{~km}$, respectively, to explore the sensitivity of the model solutions to $L_{f, \min }$. We note that although the integration lengths are not long enough for deep waters to equilibrate, they are certainly sufficient to assess any major upper-ocean impacts 
of the MLE parameterization. In the present work, our analysis is based on the time mean for years $153-172$ for $\mathrm{NY} / \mathrm{POP}^{ \pm}$and for $\mathrm{CCSM}^{ \pm}$.

\section{Appendix C. CM2G $\alpha^{ \pm}$Simulation and Implementation}

The $\mathrm{CM} 2 \mathrm{G} \alpha^{ \pm}$simulations use the same atmosphere, land, and sea-ice components as $\mathrm{CM} 2 \mathrm{M} \alpha^{ \pm}$, but with the ocean replaced by an isopycnal coordinate version of the Generalized Ocean Layered Dynamics (GOLD) ocean model. GOLD is most directly derived from the Hallberg Isopycnal Model (HIM) (see Hallberg and Gnanadesikan, 2006, for a recent realistic application of HIM), but now has the ability to use a variety of vertical coordinates (White et al., 2009). GOLD is discretized on a C-grid, unlike the B-grid discretizations of MOM4p1 and POP, so there is no particular need for filtering of the parameterization to avoid excitation of the B-grid checkerboard null mode. $\mathrm{CM} 2 \mathrm{G} \alpha^{ \pm}$uses a similar grid to $\mathrm{CM} 2 \mathrm{M} \alpha^{ \pm}$, also with a $1^{\circ}$ nominal resolution that is meridionally enhanced near the equator and a bipolar Arctic grid, but with different coastlines reflecting the ability of a C-grid model to allow flow through narrower channels than a B-grid model. CM2G $\alpha^{ \pm}$uses a total of 63 layers in the vertical - 59 isopycnal layers (layers of constant potential density referenced to $2000 \mathrm{dbar}$ ) and 4 variable density layers near the surface to represent the planetary boundary layer and facilitate its interactions with the ocean interior. The full nonlinear equation of state is used in every dynamic quantity in $\mathrm{CM} 2 \mathrm{G} \alpha^{ \pm}$; it is only the layer definitions that use a potential density (Adcroft et al., 2008). Unlike some isopycnal coordinate climate models (see Griffies et al., 2009; Megann et al., 2010), CM2G $\alpha^{ \pm}$ exactly conserves a Boussinesq mass analog and tracers like CM2M $\alpha^{ \pm}$and $\mathrm{CCSM}^{ \pm}$(Hallberg and Adcroft, 2009).

Future papers will document the comparison between $\mathrm{CM} 2 \mathrm{M} \alpha^{+}$and $\mathrm{CM} 2 \mathrm{G} \alpha^{+}$simulations more fully, but it is worth noting that the two models have quite similar surface temperature biases, both in magnitude and pattern, but that $\mathrm{CM} 2 \mathrm{G}^{+}$has much smaller temperature biases in the thermocline than CM2M $\alpha^{+}$and a much deeper (and more realistic) meridional overturning circulation than $\mathrm{CM} 2 \mathrm{M} \alpha^{+}$. The broad similarities in many of the surface properties between the $\mathrm{CM} 2 \mathrm{G} \alpha^{+}$and $\mathrm{CM} 2 \mathrm{M} \alpha^{+}$strongly suggests that the primary reasons for the differences in the response to the inclusion of the mixed layer eddy parameterization are the differences in the implementation, rather than any differences in the models states. 
Mixing in the surface boundary layer is parameterized rather differently in $\mathrm{CM} 2 \mathrm{M} \alpha^{ \pm}$and $\mathrm{CM} 2 \mathrm{G} \alpha^{ \pm}$, but they yield broadly similar mixed layer properties. CM2M $\alpha^{ \pm}$uses KPP (Large et al., 1994). CM2G $\alpha^{ \pm}$uses a two-layer refined bulk mixed layer, base on a turbulent kinetic energy budget (Hallberg, 2003). The nondimensional parameters in CM2G have been calibrated to agree with a high vertical resolution $(0.1 \mathrm{~m}) \mathrm{KPP}$ simulations in a series of year-long single-column simulations with high-frequency reanalysis forcing. In many cases the calibrated bulk mixed layer agrees better with these high-resolution KPP simulations than do KPP simulations using the $10 \mathrm{~m}$ resolution used in $\mathrm{CM} 2 \mathrm{M} \alpha^{ \pm}$(Hallberg et al., 2010). Two variable-density buffer layers between the mixed layer and the isopycnal interior allow the model to accurately simulate both the diurnal cycle of mixing layer depth and the seasonal detrainment (and reentrainment) (Hallberg et al., 2010). While KPP relies mostly on resolved shears and convective instabilities to drive mixed layer deepening, the mixed layer in GOLD also has explicit mixing arising from the surface winds.

The time stepping in $\mathrm{CM} 2 \mathrm{G} \alpha^{ \pm}$treats the dynamics and the thermodynamics as separate partial updates (Adcroft and Hallberg, 2006). The twolayer refined bulk mixed layer in $\mathrm{CM} 2 \mathrm{G} \alpha^{ \pm}$treats the tracers as though they were vertically homogenized within the mixed layer at the end of the mixed layer update (consistently with the energetic arguments that are used to determine the mixing layer depth). The velocities, however, are allowed to vary within the mixed layer, which enables the model to represent Ekman-driven convection or restratification of the mixed layer (including MLE restratification), mixed layer velocity shears as a source of energy to drive mixing, and of course parameterized effects of mixed layer eddies (Hallberg, 2003). Advection of temperature and salinity by these sheared (ageostrophic) velocities can lead to stratification within the water that was previously in the mixed layer at the start of the mixing. If there is enough energy supplied by shear or surface forcing, the old mixed layer can re-homogenize from the top down; if not, the water at the bottom detrains from the mixing layers into the variable-density buffer layers.

The implementation of the MLE parameterization in $\mathrm{CM} 2 \mathrm{G}^{+}$is relatively simple, as a similar parameterization of some effects from Young (1994) predates the implementations in $\mathrm{CM} 2 \mathrm{M}^{+}$and $\mathrm{CCSM}^{+}$by several years (Hallberg, 2003). The mixing layer depth is known from the mixed layer parameterization (it corresponds to the thickness of the top two layers) and this is used in place of the mixed layer depth in (6). This use of the 
mixing layer depth has the advantage of using a variable that is well known in the model and avoiding some of the arbitrariness from a stratification-based definition of the mixed depth; it has the disadvantage of being demonstrably wrong from the nonhydrostatic process studies with a diurnal forcing cycle of (Fox-Kemper et al., 2008b). By using the mixing layer depth instead of a stratification-based estimate of the mixed layer, the parameterization in $\mathrm{CM} 2 \mathrm{G}^{+}$will systematically underestimate the strength of restratification when there is a strong (e.g., diurnal) cycle of mixing layer depth, and ignores MLE restratification near the base of the mixed layer. For periods when the mixed layer is persistently deep, such as episodes of deep convection, the mixing layer depth and mixed layer depth (however defined) tend to be similar. The fact that the impact of the MLEs in the mixed layer turbulent kinetic energy budget is proportional to $H^{3}$ (Hallberg, 2003) and that the MLEs act to damp anomalies in the mixed layer depth will somewhat limit the adverse impacts of using the instantaneous mixing layer depth, rather than the maximum mixing layer depth over the past few days or a mixed layer depth, in the parameterization. However, this effect is likely a large part of the $1 / 5$ reduction in sensitivity to MLEs in $\mathrm{CM} 2 \mathrm{G} \alpha^{ \pm}$versus the other models.

The frontal length scale, $L_{f}$, in $\mathrm{CM} 2 \mathrm{G}$ is taken as $5 \%$ of the grid spacing; with a $1^{\circ}$ resolution this is approximately $5 \mathrm{~km}$ in the tropics, but smaller in higher latitudes. Since the mixed layer stratification cannot be estimated reliably with a bulk mixed layer model (it is assumed to be 0), approximating $L_{f}$ as a mixed layer deformation radius based on $N$ in (13) is inappropriate, although the estimate based on the horizontal buoyancy gradient would be appropriate.

In $\mathrm{CM} 2 \mathrm{G}^{+}$the overturning streamfunction is calculated from (6) and the resultant opposing transports are applied to the upper and lower mixed layers, subject to the limitation that the transports in the upper or lower mixed layers cannot exceed a CFL ratio of $\frac{1}{4}$. The resulting overturning systematically carries lighter water in the upper mixed layer and denser water in the lower mixed layer, restratifying the mixed layer as a whole.

The sensitivity of the $\mathrm{CM} 2 \mathrm{G} \alpha^{+}$to the parameterized MLEs is broadly consistent in sign and pattern with $\mathrm{CM} 2 \mathrm{M} \alpha^{+}$and $\mathrm{CCSM}^{+}$, but with reduced magnitude arising from the choices in the implementation.

Adcroft, A., Hallberg, R., 2006. On methods for solving the oceanic equations of motion in generalized vertical coordinates. Ocean Modelling 11 (1-2), $224-233$. 
Adcroft, A., Hallberg, R., Harrison, M., 2008. A finite volume discretization of the pressure gradient force using analytic integration. Ocean Modelling $22(3-4), 106-113$.

Blumen, W., Piper, M., Sep. 1999. The frontal width problem. Journal of the Atmospheric Sciences 56 (17), 3167-3172.

Boccaletti, G., Ferrari, R., Fox-Kemper, B., 2007. Mixed layer instabilities and restratification. Journal of Physical Oceanography 37 (9), 2228-2250. URL http://ams.allenpress.com/perlserv/?request= get-abstract\&doi=10.1175\%2F JP03101.1

Capet, X., Campos, E. J., Paiva, A. M., AUG 13 2008a. Submesoscale activity over the Argentinian shelf. Geophysical Research Letters 35 (15).

Capet, X., Mcwilliams, J. C., Mokemaker, M. J., Shchepetkin, A. F., 2008b. Mesoscale to submesoscale transition in the California current system. Part I: Flow structure, eddy flux, and observational tests. Journal of Physical Oceanography 38, 29-43.

Capet, X., Mcwilliams, J. C., Molemaker, M. J., Shchepetkin, A. F., 2008c. Mesoscale to submesoscale transition in the California current system. Part II: Frontal processes. Journal of Physical Oceanography 38, 44-64.

Capet, X., McWilliams, J. C., Molemaker, M. J., Shchepetkin, A. F., OCT 2008d. Mesoscale to submesoscale transition in the California current system. Part III: Energy balance and flux. Journal of Physical Oceanography 38 (10), 2256-2269.

Cole, S. T., Rudnick, D. L., Colosi, J. A., 2009. Seasonal evolution of upper ocean horizontal structure and the remnant mixed layer, in press.

Comiso, J., 1999. Bootstrap sea ice concentrations for NIMBUS-7 SMMR and DMSP SSM/I. Tech. rep., National Snow and Ice Data Center, Boulder, CO, updated 2002.

URL http://nsidc.org/data/nsidc-0079.html

Danabasoglu, G., Ferrari, R., McWilliams, J., 2008. Sensitivity of an ocean general circulation model to a parameterization of near-surface eddy fluxes. Journal of Climate 21, 1192-1208. 
Danabasoglu, G., Large, W., Tribbia, J., Gent, P., Briegleb, B., McWilliams, J., Jun. 2006. Diurnal coupling in the tropical oceans of CCSM3. Journal of Climate 19 (11), 2347-2365.

Danabasoglu, G., Large, W. G., Briegleb, B. P., 2010. Climate impacts of parameterized Nordic Sea overflows., submitted to JGR - Oceans.

Danabasoglu, G., Peacock, S., Lindsay, K., Tsumune, D., 2009. Sensitivity of cfc-11 uptake to physical initial conditions and interannually varying surface forcing in a global ocean model. Ocean Modelling 29 (1), 58-65.

D'Asaro, E. A., Sanford, T. B., Niiler, P. P., Terrill, E. J., AUG 112007. Cold wake of hurricane frances. Geophysical Research Letters 34 (15).

de Boyer Montégut, C., Madec, G., Fischer, A. S., Lazar, A., Iudicone, D., 2004. Mixed layer depth over the global ocean: An examination of profile data and a profile-based climatology. Journal of Geophysical Research 109, C12003, doi:10.1029/2004JC002378.

Delworth, T. L., Broccoli, A. J., Rosati, A., Stouffer, R. J., Balaji, V., Beesley, J. A., Cooke, W. F., Dixon, K. W., Dunne, J., Dunne, K. A., Durachta, J. W., Findell, K. L., Ginoux, P., Gnanadesikan, A., Gordon, C., Griffies, S. M., Gudgel, R., Harrison, M. J., Held, I. M., Hemler, R. S., Horowitz, L. W., Klein, S. A., Knutson, T. R., Kushner, P. J., Langenhorst, A. L., Lee, H.-C., Lin, S., Lu, L., Malyshev, S. L., Milly, P., Ramaswamy, V., Russell, J., Schwarzkopf, M. D., Shevliakova, E., Sirutis, J., Spelman, M., Stern, W. F., Winton, M., Wittenberg, A. T., Wyman, B., Zeng, F., Zhang, R., 2006. GFDL's CM2 global coupled climate models - Part 1: Formulation and simulation characteristics. Journal of Climate 19, 643-674.

Dong, S., Sprintall, J., Gille, S. T., Talley, L., JUN 13 2008. Southern ocean mixed-layer depth from argo float profiles. Journal of Geophysical Research-Oceans 113 (C6).

Dugan, J. P., Morris, W. D., Okawa, B. S., Nov. 1986. Horizontal wave number-distribution of potential-energy in the ocean. Journal of Geophysical Research-Oceans 91 (C11), 2993-3000.

Eady, E. T., 1949. Long waves and cyclone waves. Tellus 1, 33-52. 
Emery, W. J., Thomson, R. E., 2001. Data Analysis Methods in Physical Oceanography, 2nd Edition. Elsevier, Amsterdam.

Ewart, T. E., 1976. Acoustic fluctuations in open ocean - measurement using a fixed refracted path. Journal of the Acoustical Society of America 60 (1), 46-59.

Ferrari, R., Griffies, S. M., Nurser, A. J. G., Vallis, G. K., 2010. A boundaryvalue problem for the parameterized mesoscale eddy transport. Ocean Modelling 32 (3-4), 143-156.

Ferrari, R., McWilliams, J., Canuto, V., Dubovikov, M., 2008a. Parameterization of eddy fluxes near oceanic boundaries. Journal of Climate 21, 2770-2789.

Ferrari, R., McWilliams, J. C., Canuto, V. M., Dubovikov, M., JUN 15 2008b. Parameterization of eddy fluxes near oceanic boundaries. Journal of Climate 21 (12), 2770-2789.

Ferrari, R., Rudnick, D. L., JUL 15 2000. Thermohaline variability in the upper ocean. Journal of Geophysical Research-Oceans 105 (C7), 1685716883.

Ferrari, R., Young, W. R., NOV 1997. On the development of thermohaline correlations as a result of nonlinear diffusive parameterizations. Journal of Marine Research 55 (6), 1069-1101.

Fox-Kemper, B., Danabasoglu, G., Ferrari, R., Hallberg, R. W., 2008a. Parameterizing submesoscale physics in global climate models. CLIVAR Exchanges $13(1), 3-5$.

Fox-Kemper, B., Ferrari, R., 2008. Parameterization of mixed layer eddies. Part II: Prognosis and impact. Journal of Physical Oceanography 38 (6), 1166-1179. URL http://ams.allenpress.com/perlserv/?request= get-abstract\&doi=10.1175\%2F2007JP03788.1

Fox-Kemper, B., Ferrari, R., Hallberg, R., 2008b. Parameterization of mixed layer eddies. Part I: Theory and diagnosis. Journal of Physical Oceanography 38 (6), 1145-1165. 
URL http://ams.allenpress. com/perlserv/?request= get-abstract\&doi=10.1175\%2F2007JP03792.1

Franks, P., Apr. 2002. NPZ models of plankton dynamics: Their construction, coupling to physics, and application. Journal of Oceanography 58 (2), 379-387.

Gent, P. R., McWilliams, J. C., 1990. Isopycnal mixing in ocean circulation models. Journal of Physical Oceanography 20, 150-155.

Gent, P. R., Yeager, S. G., Neale, R. B., Levis, S., Bailey, D. A., 2009. Improvements in a half degree atmosphere/land version of the CCSM. Climate Dynamics.

Gnanadesikan, A., Dixon, K. W., Griffies, S. M., Balaji, V., Beesley, J. A., Cooke, W. F., Delworth, T. L., Gerdes, R., Harrison, M. J., Held, I. M., Hurlin, W. J., Lee, H.-C., Liang, Z., Nong, G., Pacanowski, R. C., Rosati, A., Russell, J., Samuels, B. L., Song, S. M., , Spelman, M. J., Stouffer, R. J., Sweeney, C. O., Vecchi, G., Winton, M., Wittenberg, A. T., Zeng, F., Zhang, R., 2006. GFDL's CM2 global coupled climate models-Part 2: The baseline ocean simulation. Journal of Climate 19, 675-697.

Griffies, S. M., 1998. The Gent-McWilliams skew flux. Journal of Physical Oceanography 28, 831-841.

Griffies, S. M., 2009. Elements of MOM4p1. NOAA/Geophysical Fluid Dynamics Laboratory, Princeton, USA, 444 pp.

Griffies, S. M., Biastoch, A., Boening, C., Bryan, F., Danabasoglu, G., Chassignet, E. P., England, M. H., Gerdes, R., Haak, H., Hallberg, R. W., Hazeleger, W., Jungclaus, J., Large, W. G., Madec, G., Pirani, A., Samuels, B. L., Scheinert, M., Sen Gupta, A., Severijns, C. A., Simmons, H. L., Treguier, A. M., Winton, M., Yeager, S., Yin, J., 2009. Coordinated ocean-ice reference experiments (cores). Ocean Modelling 26 (1-2), 1-46.

Griffies, S. M., Gnanadesikan, A., Dixon, K. W., Dunne, J. P., Gerdes, R., Harrison, M. J., Rosati, A., Russell, J., Samuels, B. L., Spelman, M. J., Winton, M., Zhang, R., 2005. Formulation of an ocean model for global climate simulations. Ocean Science 1, 45-79. 
Haine, T. W. N., Marshall, J. C., 1998. Gravitational, symmetric and baroclinic instability of the ocean mixed layer. Journal of Physical Oceanography $28,634-658$.

Hallberg, R., Adcroft, A., 2009. Reconciling estimates of the free surface height in lagrangian vertical coordinate ocean models with mode-split time stepping. Ocean Modelling 29 (1), 15-26.

Hallberg, R., Gnanadesikan, A., DEC 2006. The role of eddies in determining the structure and response of the wind-driven southern hemisphere overturning: Results from the modeling eddies in the southern ocean (meso) project. Journal of Physical Oceanography 36 (12), 2232-2252.

Hallberg, R., Harrison, M., Anderson, W., Adcroft, A., 2010. Representing the diurnal cycle in a climate model with a refined bulk mixed layer, in preparation.

Hallberg, R. W., 2003. The suitability of large-scale ocean models for adapting parameterizations of boundary mixing and a description of a refined bulk mixed layer model, in press.

Hodges, B. A., Rudnick, D. L., Sep. 2006. Horizontal variability in chlorophyll fluorescence and potential temperature. Deep-Sea Research Part IOceanographic Research Papers 53 (9), 1460-1482.

Hosegood, P., Gregg, M. C., Alford, M. H., 2006. Sub-mesoscale lateral density structure in the oceanic surface mixed layer. Geophysical Research Letters 33 (L22604), doi:10.1029/2006GL026797.

Hoskins, B. J., Bretherton, F. P., 1972. Atmospheric frontogenesis models: Mathematical formulation and solution. Journal of Atmospheric Sciences 29 .

Inoue, R., Harcourt, R. R., Gregg, M. C., 2009. Mixing rates across the gulf stream, Part 2: Implications for non-local parameterization of vertical fluxes in baroclinic surface boundary layers, in preparation.

Jayne, S. R., Jul. 2009. The impact of abyssal mixing parameterizations in an ocean general circulation model. Journal of Physical Oceanography 39 (7), 1756-1775. 
Jochum, M., Danabasoglu, G., Holland, M., Kwon, Y.-O., Large, W., 2008. Ocean viscosity and climate. Journal of Geophysical ResearchIn press.

Katz, E. J., 1975. Tow spectra from MODE. Journal of Geophysical Research 80 (9), 1163-1167.

Key, R., Kozyr, A., Sabine, C., Lee, K., Wanninkhof, R., Bullister, J., Feely, R., Millero, F., Mordy, C., Peng, T., Dec. 2004. A global ocean carbon climatology: Results from global data analysis project (glodap). Global Biogeochemical Cycles 18 (4).

Klein, P., Hua, B. L., Lapeyre, G., Capet, X., Le Gentil, S., Sasaki, H., AUG 2008. Upper ocean turbulence from high-resolution 3d simulations. Journal of Physical Oceanography 38 (8), 1748-1763.

Klein, P., Lapeyre, G., 2009. The Oceanic Vertical Pump Induced by Mesoscale and Submesoscale Turbulence. Annual Review of Marine Science 1, 351-375.

Lapeyre, G., Klein, P., Hua, B. L., 2006. Oceanic restratification forced by surface frontogenesis. Journal of Physical Oceanography 36, 1577-1590.

Large, W., Danabasoglu, G., Doney, S., McWilliams, J., Nov. 1997. Sensitivity to surface forcing and boundary layer mixing in a global ocean model: Annual-mean climatology. Journal of Physical Oceanography 27 (11), 2418-2447.

Large, W., McWilliams, J., Doney, S., 1994. Oceanic vertical mixing: A review and a model with a vertical k-profile boundary layer parameterization. Rev. Geophys. 32 (4), 363-403.

Large, W. G., Yeager, S. G., 2004. Diurnal to decadal global forcing for ocean and sea-ice models: the data sets and flux climatologies. NCAR Technical Note, NCAR/TN-460+STR.

Le Traon, P. Y., Klein, P., Hua, B. L., Dibarboure, G., May 2008. Do altimeter wavenumber spectra agree with the interior or surface quasigeostrophic theory? Journal of Physical Oceanography 38 (5), 1137-1142.

Levitus, S., 1982. Climatological atlas of the world ocean. U.S. Government Printing Office 13, NOAA, Washington, D.C., 163 pp. 
Levitus, S., Boyer, T., Concright, M., Johnson, D., O'Brien, T., Antonov, J., Stephens, C., Garfield, R., 1998. World ocean database 1998, volume I: Introduction. NOAA Atlas NESDIS 18, U. S. Government Printing Office, Washington, D. C.

Lévy, M., Klein, P., Tréguier, A.-M., Iovino, D., Madec, G., Masson, S., Takahashi, K., 2010. Modifications of gyre circulation by sub-mesoscale physics. Ocean Modelling 34, 1-15.

Levy, M., Visbeck, M., Naik, N., May 1999. Sensitivity of primary production to different eddy parameterizations: A case study of the spring bloom development in the northwestern mediterranean sea. Journal of Marine Research 57 (3), 427-448.

Luyten, J. R., Pedlosky, J., Stommel, H., 1983. The ventilated thermocline. Journal of Physical Oceanography 13, 292-309.

Mahadevan, A., Archer, D., Jan. 2000. Modeling the impact of fronts and mesoscale circulation on the nutrient supply and biogeochemistry of the upper ocean. Journal of Geophysical Research-Oceans 105 (C1), 12091225 .

Mahadevan, A., Campbell, J., Oct. 2002. Biogeochemical patchiness at the sea surface. Geophysical Research Letters 29 (19).

Mahadevan, A., Tandon, A., Ferrari, R., 2010. Rapid changes in mixed layer stratification driven by submesoscale instabilities and winds. J. Geophys. Res. 115, C03017.

Marshall, J., Adcroft, A., Hill, C., Perelman, L., Heisey, C., March 15, 1997. A finite-volume, incompressible Navier-Stokes model for studies of the ocean on parallel computers. Journal of Geophysical Research 102 (C3), $5753-5766$.

Marshall, J. C., Nurser, G., 1992. Fluid dynamics of oceanic thermocline ventilation. Journal of Physical Oceanography 22, 1315-1329.

Megann, A. P., New, A. L., Blaker, A. T., Sinha, B., 2010. The sensitivity of a coupled climate model to its ocean component. Journal of Climate In press. 
Monterey, G. L., Levitus, S., 1997. Climatological cycle of mixed layer depth in the world ocean. Tech. rep., U.S. Gov. Printing Office, NOAA NESDIS.

Neale, R. B., Richter, J. H., Jochum, M., NOV 15 2008. The impact of convection on ENSO: From a delayed oscillator to a series of events. Journal of Climate 21 (22), 5904-5924.

Oschlies, A., 2002. Improved representation of upper-ocean dynamics and mixed layer depths in a model of the north atlantic on switching from eddypermitting to eddy-resolving grid resolution. Journal of Physical Oceanography $32,2277-2298$.

Pollard, R. T., Regier, L. A., 1992. Vorticity and vertical circulation at an ocean front. Journal of Physical Oceanography 22, 609-625.

Price, J. F., 1981. Upper ocean response to a hurricane. Journal of Physical Oceanography 11, 153-175.

Price, J. F., Morzel, J., Niiler, P. P., Jul. 2008. Warming of sst in the cool wake of a moving hurricane. Journal of Geophysical Research-Oceans $113(\mathrm{C} 7)$.

Redi, M. H., 1982. Oceanic isopycnal mixing by coordinate rotation. Journal of Physical Oceanography 12, 1154-1158.

Rudnick, D. L., Ferrari, R., JAN 22 1999. Compensation of horizontal temperature and salinity gradients in the ocean mixed layer. Science 283 (5401), 526-529.

Samelson, R. M., Chapman, D. C., 1995. Evolution of the instability of a mixed-layer front. Journal of Geophysical Research 100, 6743-6759.

Samelson, R. M., Paulson, C. A., Mar. 1988. Towed thermistor chain observations of fronts in the sub-tropical North Pacific. Journal of Geophysical Research-Oceans 93 (C3), 2237-2246.

Smith, R., Gent, P., 2004a. Anisotropic gent-mcwilliams parameterization for ocean models. Journal of Physical Oceanography 34, 2541-2564.

Smith, R., Jones, P., Briegleb, B., Bryan, F., Danabasoglu, G., Dennis, J., Dukowicz, J., Eden, C., Fox-Kemper, B., Gent, P., Hecht, M., Jayne, S., 
M. Jochum, W. Large, K. L., Maltrud, M., Norton, N., Peacock, S., Vertenstein, M., Yeager, S., MAR 2010. The Parallel Ocean Program (POP) Reference Manual. Tech. Rep. LAUR-10-01853, Los Alamos National Laboratory.

URL http://www. ccsm.ucar.edu/models/ccsm4.0/pop

Smith, R. D., Gent, P. R., 2004b. Reference manual for the parallel ocean program (pop): Ocean component of the community climate system model (ccsm2.0 and 3.0). Tech. Rep. LA-UR-02-2484, Los Alamos National Laboratory, Los Alamos, NM.

URL http://www.ccsm.ucar.edu/models/ccsm3.0/pop

Spall, M. A., Feb 1995. Frontogenesis, subduction, and cross-front exchange at upper ocean fronts. Journal of Geophysical Research-Oceans 100 (C2), $2543-2557$.

Spall, S., Richards, K., Jul. 2000. A numerical model of mesoscale frontal instabilities and plankton dynamics - I. Model formulation and initial experiments. Deep-Sea Research Part I-Oceanographic Research Papers 47 (7), $1261-1301$.

St Laurent, L., Simmons, H., Jayne, S., Dec. 2002. Estimating tidally driven mixing in the deep ocean. Geophysical Research Letters 29 (23).

Steele, M., Morley, R., Ermold, W., 2001. Phc: A global ocean hydrography with a high-quality arctic ocean. Journal of Climate 14 (9), 2079-2087.

Stone, P. H., 1970. On non-geostrophic baroclinic stability: Part II. Journal of the Atmospheric Sciences 27, 721-726.

Strass, V. H., Jan. 1992. Chlorophyll patchiness caused by mesoscale upwelling at fronts. Deep-Sea Research Part A-Oceanographic Research Papers 39 (1A), 75-96.

Tandon, A., Garrett, C., 1994. Mixed layer restratification due to a horizontal density gradient. Journal of Physical Oceanography 24, 1419-1424.

Taylor, J. R., Ferrari, R., Mar. 2009. On the equilibration of a symmetrically unstable front via a secondary shear instability. Journal of Fluid Mechanics 622, 103-113. 
Taylor, J. R., Ferrari, R., 2010. Buoyancy and wind-driven convection at mixed layer density fronts, submitted.

Thomas, L. N., Ferrari, R., NOV 2008. Friction, frontogenesis, and the stratification of the surface mixed layer. Journal of Physical Oceanography 38 (11), 2501-2518.

Thomas, L. N., Lee, C. M., 2005. Intensification of ocean fronts by down-front winds. Journal of Physical Oceanography 35, 1086-1102.

Treguier, A. M., Held, I. M., Larichev, V. D., 1997. On the parameterization of quasi-geostrophic eddies in primitive equation ocean models. Journal of Physical Oceanography 27, 567-580.

Tzella, A., Haynes, P. H., 2007. Small-scale spatial structure in plankton distributions. Biogeosciences 4 (2), 173-179.

Webb, A. A., Fox-Kemper, B., Peacock, S., Large, W. R., 2010. Global model sensitivity to parameterizing langmuir circulation, in preparation for Ocean Modelling.

White, L., Adcroft, A., Hallberg, R., Dec. 2009. High-order regriddingremapping schemes for continuous isopycnal and generalized coordinates in ocean models. Journal of Computational Physics 228 (23), 8665-8692.

Yeager, S. G., Jochum, M., 2009. The connection between Labrador Sea buoyancy loss, deep western boundary current strength, and Gulf Stream path in an ocean circulation model. Ocean Modelling 30 (2-3), 207-224.

Young, W. R., 1994. The subinertial mixed layer approximation. Journal of Physical Oceanography 24, 1812-1826. 


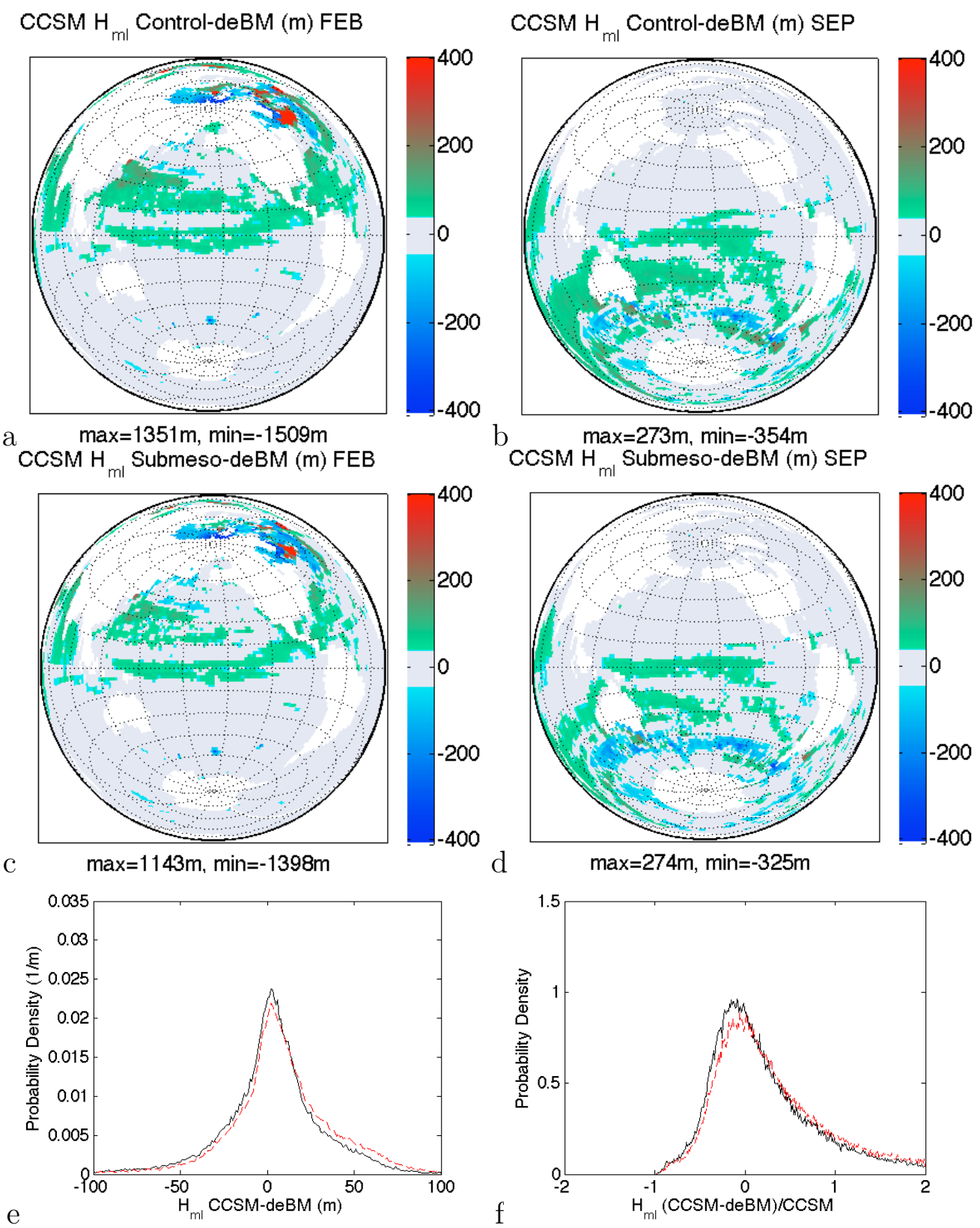

Figure 5: Figures demonstrating the change in mixed layer depth bias (compared to updated climatology of de Boyer Montégut et al., 2004) from $\mathrm{CCSM}^{-}(\mathrm{a}, \mathrm{b})$ to $\mathrm{CCSM}^{+}(\mathrm{c}, \mathrm{d})$ in February (a,c) and September (b,d). (e)Probability density function of the mixed layer depth bias for all climatology gridpoints, all months, where the climatology value exists. (f) Probability density function of relative mixed layer depth bias (bottom, right) for $\mathrm{CCSM}^{-}$(red, dashed) to $\mathrm{CCSM}^{+}$(black, solid). 


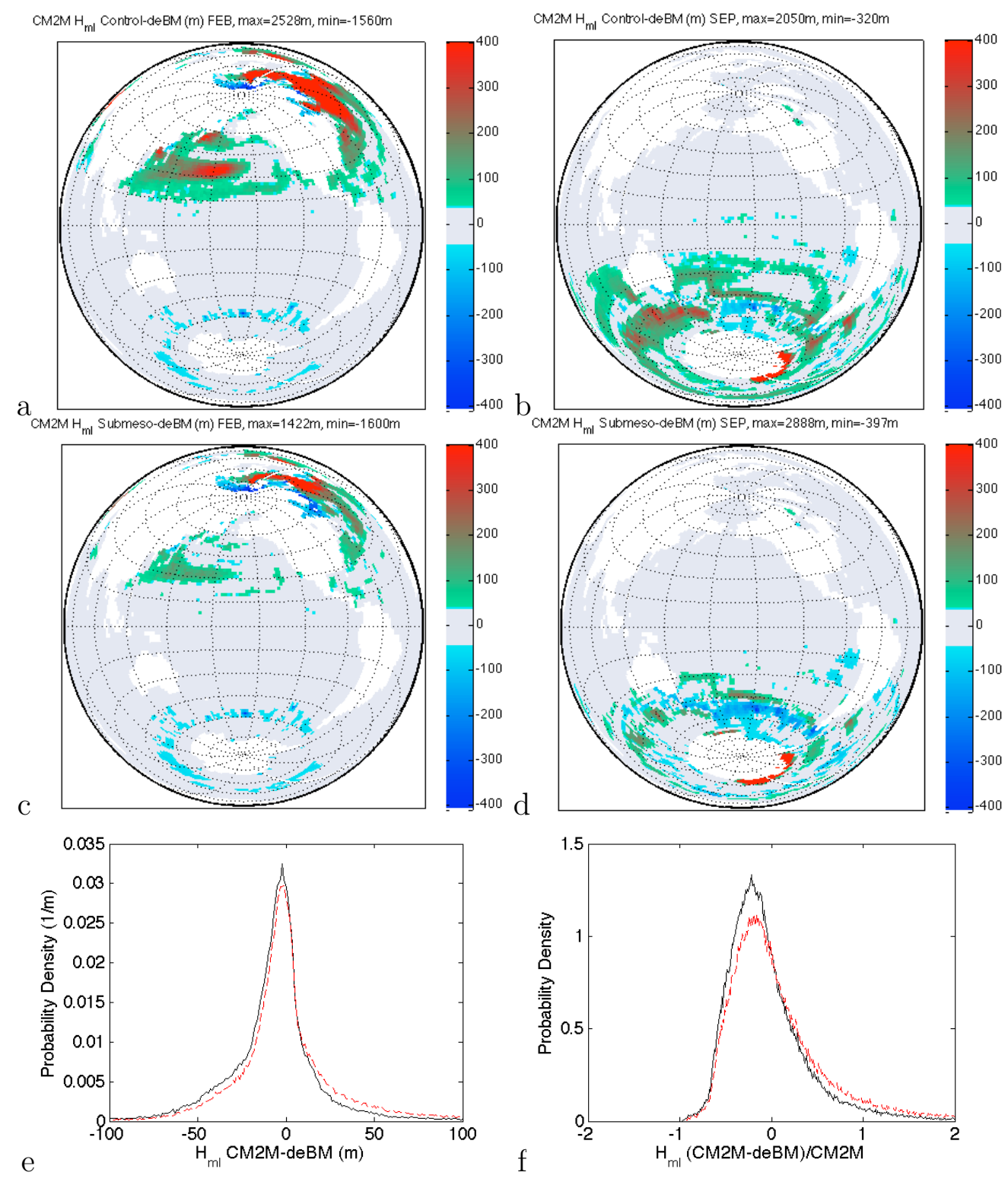

Figure 6: As in Fig. 5, but for $\mathrm{CM} 2 \mathrm{M} \alpha^{-}$(upper, red lower) and $\mathrm{CM} 2 \mathrm{M} \alpha^{+}$(middle, black lower). 

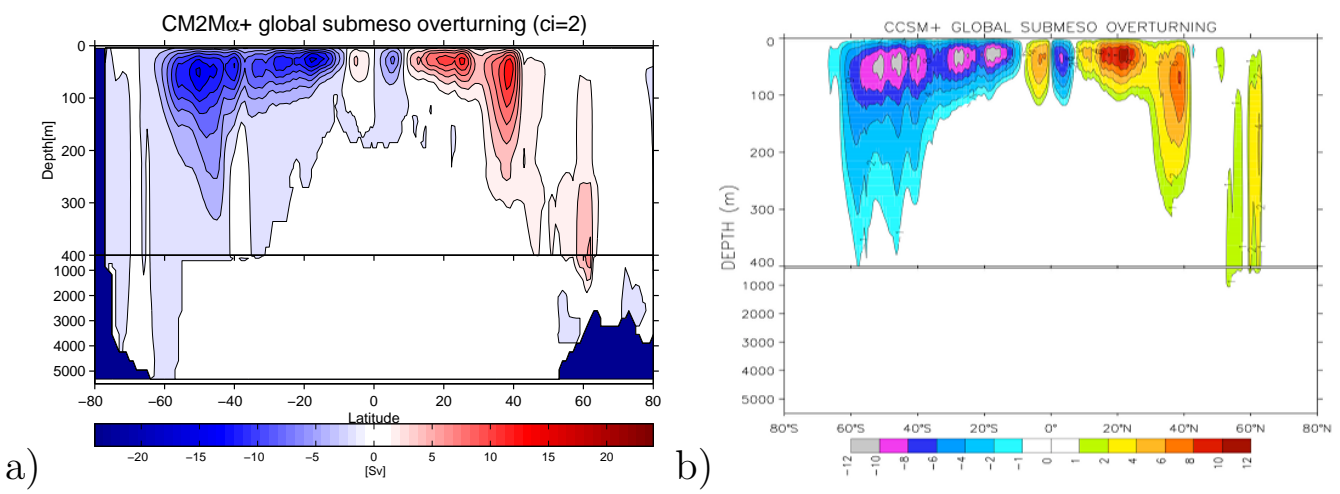

Figure 7: The 20yr mean meridional overturning streamfunction (Sv) from the MLE parameterization in a) $\mathrm{CM}_{2} \mathrm{M}^{+}$and b) $\mathrm{CCSM}^{+}$. The contour interval is $2 \mathrm{~Sv}$.

a)

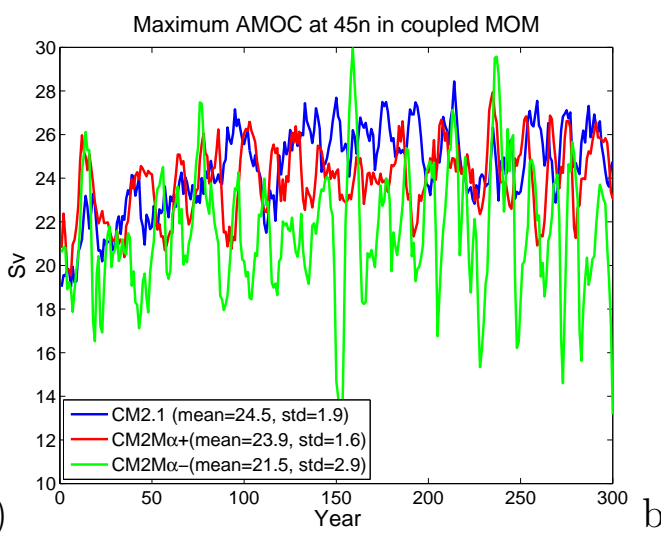

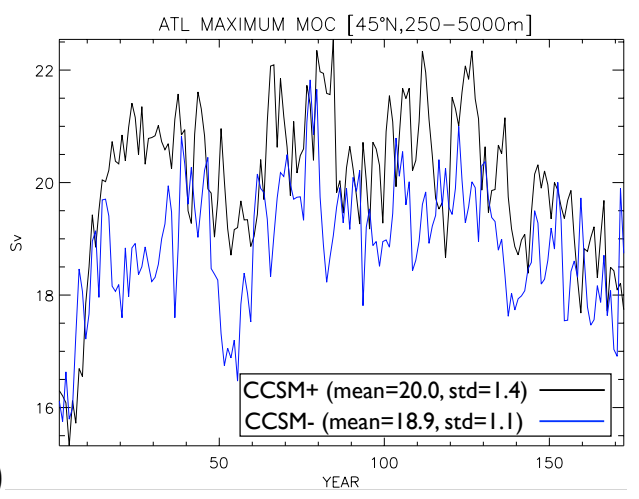

Figure 8: (a) Time series of annual mean Atlantic meridional overturning index (maximum overturning streamfunction at $45^{\circ} \mathrm{N}$ ). The blue line is from CM2.1, which uses no submesoscale parameterization and the implementation of GM90 according to Treguier et al. (1997) (see Appendix A). The red line is CM2M $\alpha^{+}$, using the Ferrari et al. (2008a) implementation of Gent and McWilliams (1990). The green line is CM2M $\alpha^{-}$, which also uses Ferrari et al. (2008a). (b) The AMOC in $\mathrm{CCSM}^{+}$and $\mathrm{CCSM}^{-}$are similarly variable to $\mathrm{CM} 2 \mathrm{M} \alpha^{+}$(note y-axis scale). 


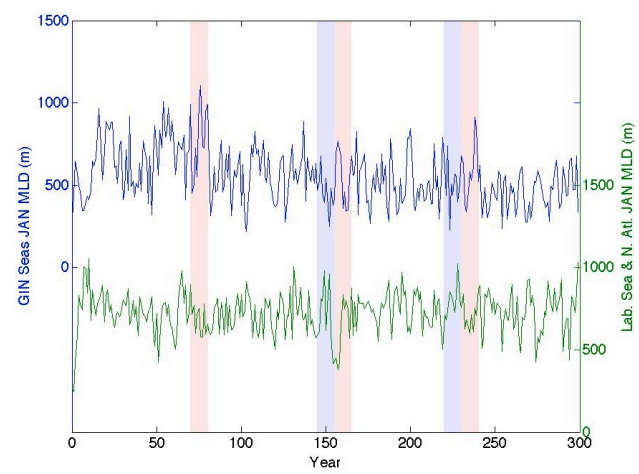

Figure 9: Time series of January mixed layer depth in different regions where deep convection occurs in CM2M $\alpha^{-}$. Left axis shows GIN seas (10W:15E, $\left.65 \mathrm{~N}: 80 \mathrm{~N}\right)$, right axis shows mean over Labrador Sea (60W:42W, 45N:65N) and Irminger Sea/N. Atlantic convection region ( $42 \mathrm{~W}: 5 \mathrm{~W}, 45 \mathrm{~N}: 65 \mathrm{~N})$. Pink shaded regions show times of anomalous positive AMOC from Fig. 8a, and blue shaded regions show times of anomalous negative AMOC.
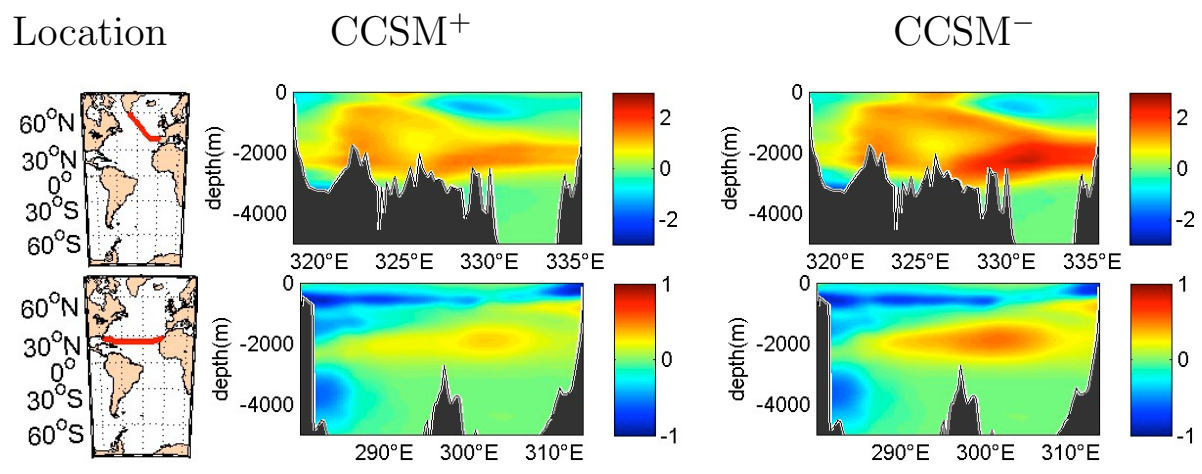

Figure 10: CFC-11 concentration bias (pmol $/ \mathrm{kg}$, observed range about 0 to $2 \mathrm{pmol} / \mathrm{kg}$ ) in $\mathrm{CCSM}^{ \pm}$at the correct simulation year after CFC-11 introduction to simulate WOCE sections A05 (upper) and A25 (lower). 

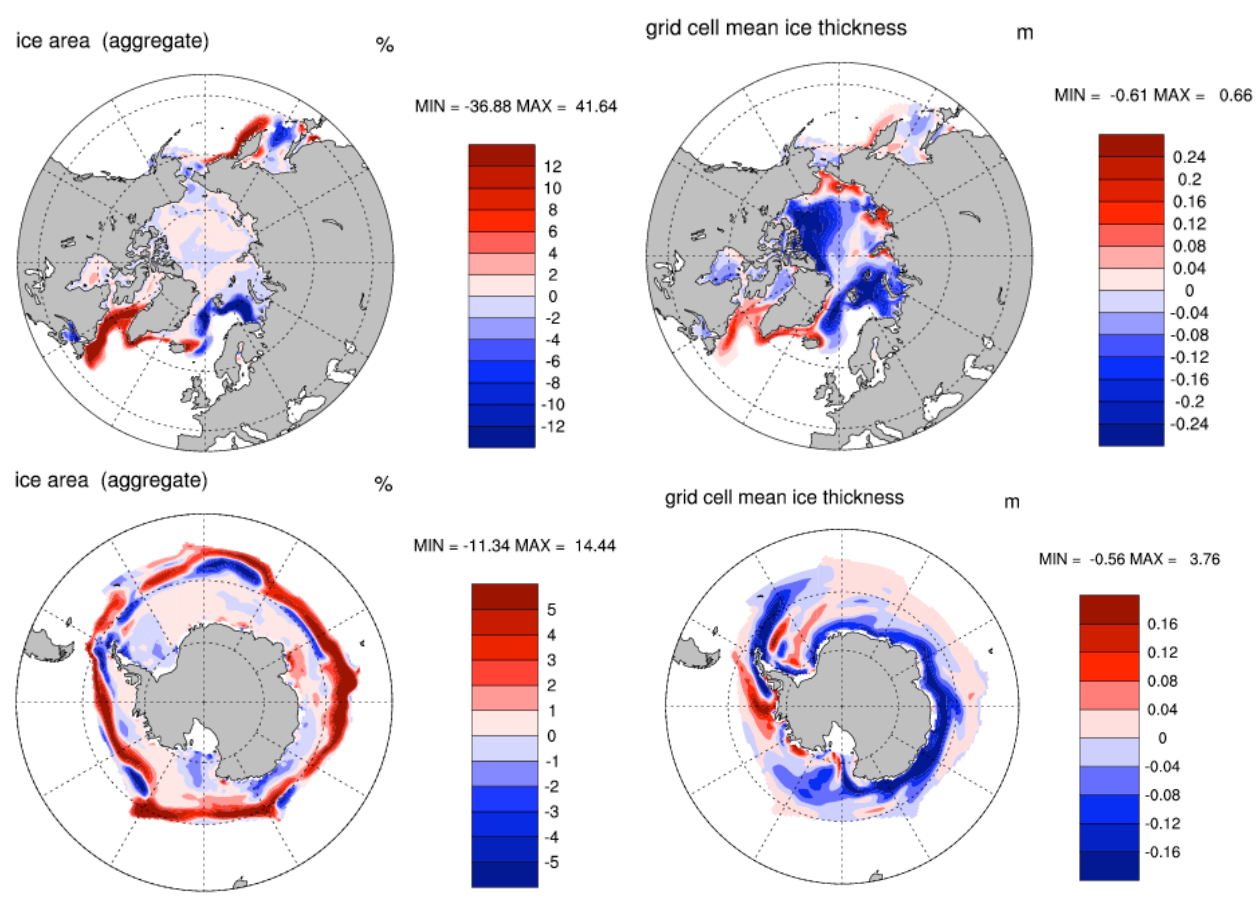

$\%$

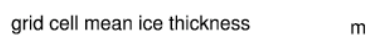

MIN $=-11.34$ MAX $=14.44$
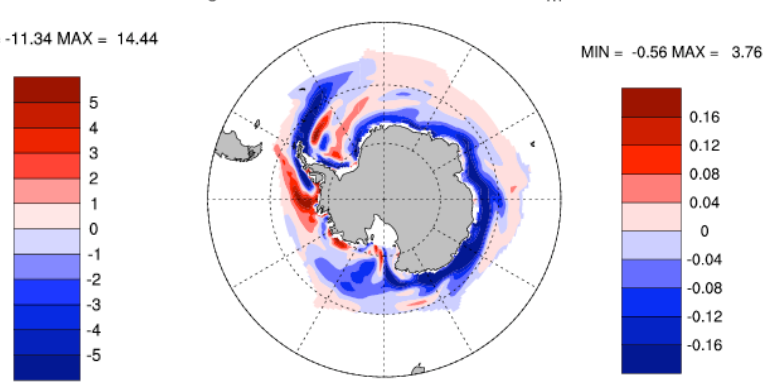

Figure 11: Wintertime sea ice sensitivity to introduction of MLE parameterization $\left(\mathrm{CCSM}^{+}\right.$minus $\left.\mathrm{CCSM}^{-}\right)$: January to March Northern Hemisphere a) ice area and b) thickness and July to September Southern Hemisphere c) ice area and d) thickness. 